\title{
Microwave properties and characterization of co-evaporated BSCCO thin films
}

\author{
F A MIrandat, C M Choreył, M A Stan§, C E Nordgren\|, \\ R Y Kworfl and T $S$ Kalkurf \\ $\uparrow$ National Aeronautics and Space Administration, Lewls Research Center. \\ Cleveland, $\mathrm{OH} \mathbf{4 4 1 3 5}$ \\ ¥ Sverdrup Technology, Inc. Lewis Research Center Group, Brook Park, OH 44142 \\ 5 Department of Physics, Kent State University, Kent, OH 44242 \\ I Department of Physics, Case Western Reserve University. Cleveland, $\mathrm{OH} \mathbf{4 4 1 0 6}$ \\ I Department of Electrical and Computer Engineering. University of Colorado at \\ Colorado Springs, Colorado Springs, CO 80933, USA
}

Recelved 25 February 1992, in final form 21 April 1992

\begin{abstract}
Abetract. An extensive characterization of $\mathrm{Bi}-\mathrm{Sr}-\mathrm{Ca}-\mathrm{Cu}-\mathrm{O}$ (BSCCO) thin films deposited by co-evaporation on $\mathrm{LaAlO}_{3}$ and $\mathrm{SrTIO}_{3}$ substrates has been performed. The films had a $T_{c}(R=0)$ of $\sim 78 \mathrm{~K}$, and were predominantly $c$-axis oriented, with critical current densities $W_{c}$ ) at $4.5 \mathrm{~K}$ of $1.6 \times 10^{6}$ and $1.1 \times 10^{6} \mathrm{~A} \mathrm{~cm}^{-2}$, for the samples on $\mathrm{SrTiO}_{3}$ and $\mathrm{LaAlO}_{3}$ respectively. The microwave properties of the films were examined by three techniques. The complex conductivity $\left(\sigma^{*}-\sigma_{1}-j \sigma_{2}\right)$ and the magnetic penetration depth $(\lambda)$ were measured by power transmission at $30.6 \mathrm{GHz}$; the surface resistance $\left(R_{2}\right)$ was measured using a cavity resonator at $58.9 \mathrm{GHz}$, and the transmlssion Ilne losses were determined by measuring the quality factor $(Q)$ of a linear microstrip resonator at 10.4 and $20.2 \mathrm{GHz}$. The complex conductivity for the film on LaA1O 3 was determined to be $(2.0-j 10) \times 10^{5} \mathrm{~s} \mathrm{~m}^{-1}$ at $77 \mathrm{~K}$. It was observed that in the superconducting state $\sigma$, deviates from both the Bardeen-Cooper-Schrieffer (BCS) theory and the two-fluid model. Values of $\lambda$ were found to be $\sim 2.0$ and $1.1 \mu \mathrm{m}$ at $77 \mathrm{~K}$ and $20 \mathrm{~K}$ respectively, and were obtained for the film on $\mathrm{LaAlO}_{3}$. The value of $\lambda$ at $20 \mathrm{~K}$ was approximately three times larger than that of BSCCO single crystals. $R$, velues of 865 and $1391 \mathrm{~m} \Omega$ were obtained for the films on $\mathrm{SrTIO}_{3}$ and $\mathrm{LaAlO}_{3}$, respectively, at $77 \mathrm{~K}$ and $58.9 \mathrm{GHz}$. Unloaded $Q$ factors at $20 \mathrm{~K}$ of $\sim 1100$ and 800 at 10.4 and $20.2 \mathrm{GHz}$ respectlvely, were measured for the BSCCO resonator. Unloaded $Q$ values of 290 and 405 at $20 \mathrm{~K}$ were obtained at $10.4 \mathrm{GHz}$ and $20.2 \mathrm{GHz}$ respectively, for an all gold (Au) resonator.
\end{abstract}

\section{Introduction}

High transition temperature superconductors (HTs) have potential for microwave applications due to their low loss and dispersion as compared with typically used conductors such as copper $(\mathrm{Cu})$ and gold $(\mathrm{Au})$. Therefore, it is not surprising that to date a large number of measurements at microwave frequencies on Hrs properties such as surface resistance $\left(R_{2}\right)$, complex conductivity $\left.Y^{*}=\sigma_{1}-\mathrm{j} \sigma_{2}\right)$, and magnetic penetration depth $(\lambda)$, have been reported. Most of the work so far has been performed on the $\mathrm{YBa}_{2} \mathrm{Cu}_{3} \mathrm{O}_{7-}$ (YBCO) compound [1-7], mainly because of its single phase and simplicity of fabrication. However, studies of the $\mathrm{Bi}-\mathrm{Sr}-\mathrm{Ca}-\mathrm{Cu}-\mathrm{O}$ (BSCCO) compound have been performed by several research groups since this material offers the advantage of being relatively insensitive to exposure to atmosphere and handling, and because of its great stability with respect to thermal cycling [8]. In spite of the number of studies on BSCCO thin films, data on $R$, and $\sigma^{*}$ at microwave frequencies are still scarce $[9,10]$.

In this paper we report on the structural, $D C$ and microwave properties of two BSCCO thin films deposited by co-evaporation on $\mathrm{LaAlO}_{3}$ and $\mathrm{SrTiO}_{3}$ substrates. The films were characterized by scanning electron microscopy (SEM), x-ray diffraction (XRD) analysis, by $D C$ transition temperature $\left(T_{c}\right)$ and critical current density $\left(J_{c}\right)$ measurements. The microwave properties of the films were determined from $R$, measurements using resonant cavity techniques, and power transmission measurements. The $R$, of the film on $\mathrm{LaAlO}_{3}$ was also measured using a linear resonator

( 1992 U.S. Govemment. Reprinted, with permission, from the U.S. Government. 


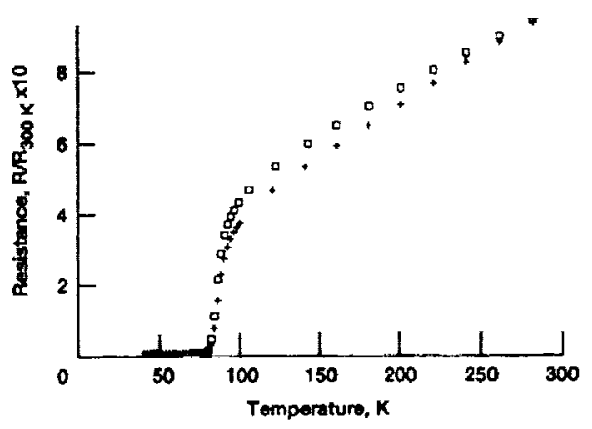

Figure 1. Normalized resistance against temperature for BSCCO thin films $(3000 A)$ on $\mathrm{SrTIO}_{3}\left(+: T_{\mathrm{c}}(R=0)=78.2\right.$ $\mathrm{K})$ and $\mathrm{LaAlO}_{3}\left(\square: T_{c}(R=0)=78 \mathrm{~K}\right)$ substrates.

method, since knowledge of the microwave signal propagation along transmission lines is of interest for practical microwave applications.

\section{Structure and DC propertles}

Our measurements were made on BSCCO superconducting films approximately $3000 \AA$ thick deposited by co-evaporation on to (100) $\mathrm{LaAlO}_{3}$ and $(100) \mathrm{SrTiO}_{3}$ substrates 0.010 in thick. The details of the BSCCO film preparation can be found elsewhere [11]. The $T_{c}(R=0)$ of the films was determined using standard four-pointprobe measurement techniques. $T_{c}$ values of 78.2 and 78.0 K were measured for the films on $\mathrm{SrTiO}_{3}$ and $\mathrm{LaAlO}_{3}$ respectively (figure 1 ). Both films have a transition width $(\Delta T)$ of $\sim 10 \mathrm{~K}$, which is consistent with previously reported resistivity data for BSCCO thin films [12]. The zero temperature intercept $\left(\boldsymbol{R}_{\mathrm{o}}\right)$ is lower for the film on $\mathrm{SrTiO}_{3}$, and suggests a higher degree of $c$-axis texturing, where the $c$ axis is perpendicular to the substrate plane.

Figure 2 shows SEM micrographs of the films under study. The observed surface roughness is typical of films grown by high temperature ex-situ anneal. However, surface roughness alone has not been shown to be detrimental to microwave properties of HTs thin films [?, 13]. Note that the background structure shows the plate-like structure typical of the BSCCO system. The typical grain size for these films was between 2 and $10 \mu \mathrm{m}$. XRD analysis of these films showed that they were predominantly oriented with the $c$ axis perpendicular to the film plane, although unknown peaks were observed in both samples, as shown in figure 3 . The $c$-axis lattice parameter agrees within 1 per cent of that corresponding to single crystals [14].

Magnetization hysteresis measurements were performed using a Quantum Design Magnetic Property Measurement System (MPMS). For these measurements, rectangular samples were cut from the films on $\mathrm{SrTiO}_{3}$ and $\mathrm{LaAlO}_{3}$, and the samples were oriented with the $a-b$ plane normal to the magnetic field $(H)$. Figure 4 shows magnetization hysteresis loops for both films.

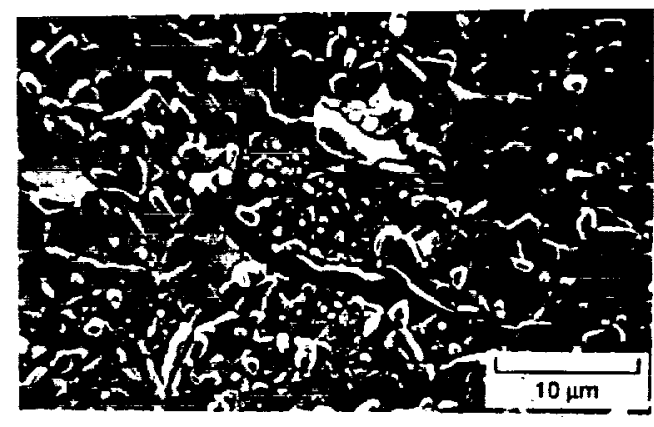

(a)

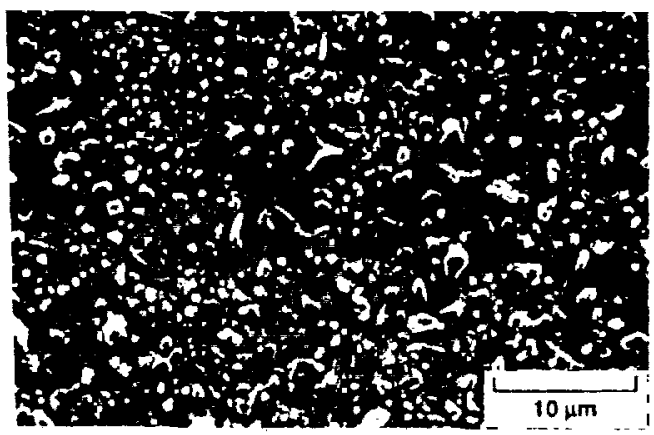

(b)

Flgure 2. Scanning electron micrographs of the surface of co-evaporated $\left(3000\right.$ A) BSCCO thin films on (a) $\mathrm{SrTiO}_{3}$. and $(b)$ LaAlO $_{3}$.
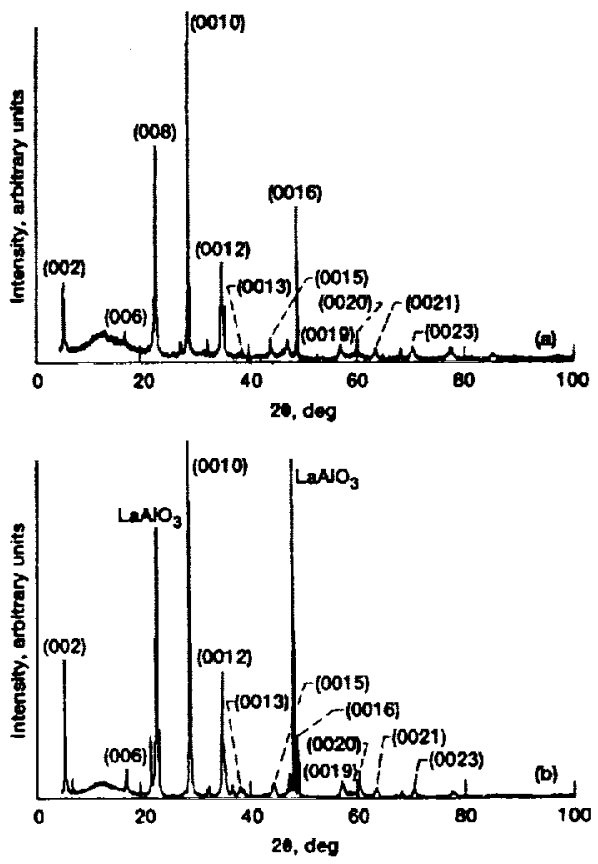

Flqure 3. X-ray diffraction pattern of $3000 \AA$ BSCCO HTS thin films on (a) $\mathrm{SrTiO}_{3}$, and (b) $\mathrm{LaAlO}_{3}$ substrates. The films are predominantly the $\mathrm{Bi}_{2} \mathrm{Sr}_{2} \mathrm{Ca}_{1} \mathrm{Cu}_{2} \mathrm{O}_{n}$ (2212) phase with the $c$ axis perpendicular to the substrate. 

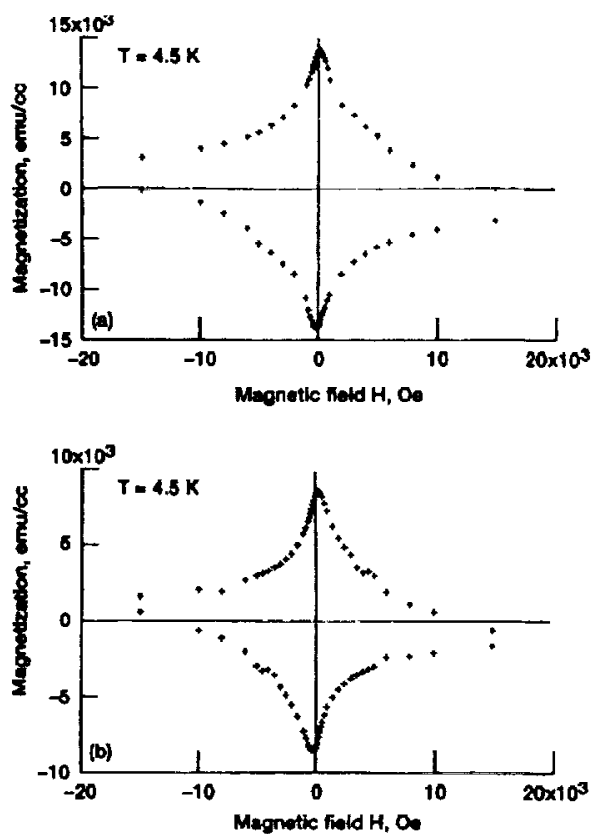

Floure 4. Magnetization hysteresis loops for BSCCO thin films $(3000 \mathrm{~A})$ on $(a) \mathrm{SrTiO}_{3}$, and (b) $\mathrm{LaAlO}_{3} ; \mathrm{H}$ parallel to the $c$ axis.

Using Bean's model [15], and assuming a circular current path, we obtained $J$ values at $4.5 \mathrm{~K}$ of $1.6 \times 10^{6}$ and $1.1 \times 10^{6} \mathrm{~A} \mathrm{~cm}^{-2}$ for the films on $\mathrm{SrTiO}_{3}$ and $\mathrm{LaAlO}_{3}$ respectively. $J_{c}$ values for both films are listed in table 1 as a function of temperature. Note that for all temperatures the $J_{c}$ obtained for the film on $\mathrm{SrTiO}_{3}$ is larger than that for the film on $\mathrm{LaAlO}_{3}$, which may be a result of better epitaxy on the $\mathrm{SrTiO}_{3}$ substrate. In addition, the $J_{c}$ values for both films at $40 \mathrm{~K}$ agree well with the $J_{c} \sim 1.5 \times 10^{5} \mathrm{~A} \mathrm{~cm}^{-2}$ reported at $40 \mathrm{~K}$ for laser-ablated BSCCO thin films ( $\sim 3000$ A) on $\mathrm{MgO}$ [12].

\section{Characterization of 8scCo films at microwave frequencies}

\subsection{Power transmission measurements}

Power transmission measurements were performed on the samples at frequencies from 26.5 to $40.0 \mathrm{GHz}$ (Ka-

Table 1. Magnetic $J_{c}$ for BSCCO thin films on $\mathrm{SrTiO}_{3}$ and $\mathrm{LaAlO}_{3}$ substrates.

\begin{tabular}{lll}
\hline \multirow{2}{*}{$\begin{array}{l}\text { Temperature } \\
(\mathrm{K})\end{array}$} & \multicolumn{2}{c}{$J_{\mathrm{c}}\left(\mathrm{A} \mathrm{cm}^{-2}\right)$} \\
\cline { 2 - 3 } & $\mathrm{SrTIO}_{3}$ & $\mathrm{LaAlO}_{3}$ \\
\hline 4.5 & $1.6 \times 10^{6}$ & $1.1 \times 10^{6}$ \\
20.0 & $1.0 \times 10^{6}$ & $6.7 \times 10^{5}$ \\
40.0 & $2.7 \times 10^{5}$ & $1.0 \times 10^{5}$ \\
\hline
\end{tabular}
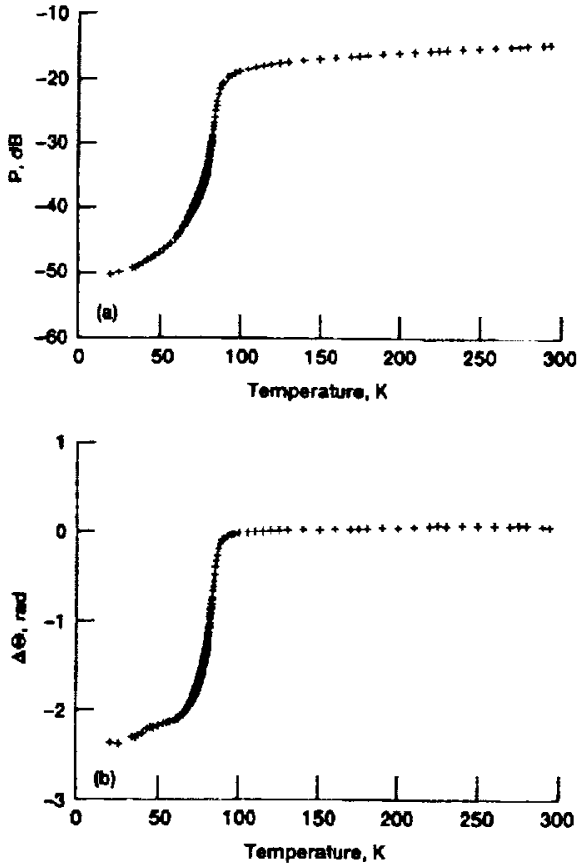

Flouro 5. Magnitude, $P,(a)$ and relative phase, $\Delta \theta=\theta_{300 \times}$ $-\theta(T)(b)$ of the fractional transmitted power for a co-evaporated BSCCO thin film $(3000 \mathrm{~A})$ on $\mathrm{LaAlO}_{3}$ at $30.6 \mathrm{GHz}$.

band), and at temperatures from 300 to $20 \mathrm{~K}$. The details of the experimental configuration and measurement procedures have been previously reported [7]. The main components of the experimental apparatus are an HP-8510B network analyser and a closed-cycle helium gas refrigerator, both controlled by an HP 900-216 computer. The network analyser is coupled to the refrigerator by $\mathrm{Ka}$-band rectangular waveguides. The measurement technique compares the transmitted signal with the incident microwave signal to determine the power transmission coefficient. All the measurements were made under vacuum $\left(<10^{-3}\right.$ Torr $)$ in a vacuum can with input/output ports for the waveguides designed for the refrigerator. Inside the vacuum can the sample was oriented perpendicular to the microwave source by clamping it between two waveguide flanges thermally connected to the cold head of the refrigerator through a gold-plated copper plate. The film side of the sample was directed towards the incident microwave signal. The system was calibrated before the beginning of each measurement cycle to account for the impedance and spurious reflections of the waveguide network. Background attenuation and phase corrections were made by subtracting the transmitted power as a function of temperature in the absence of the sample from the data obtained with the sample in place.

Figure 5 shows a plot of the magnitude $(P)$ and relative phase $\left(\Delta \theta\right.$, where $\Delta \theta=\theta_{\mathrm{RT}}-\theta(T)$, with $\theta_{\mathrm{RT}}$ the phase value at room temperature) at $30.6 \mathrm{GHz}$ of the fractional transmitted power for the film on the $\mathrm{LaAlO}_{3}$ 

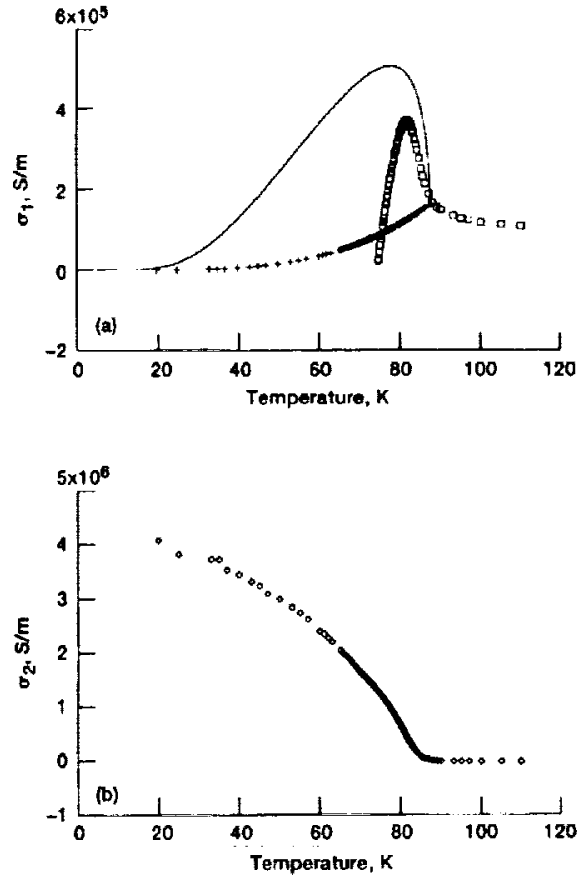

Figure 6. Real (a) and imaginary (b) parts of the complex conductivity against temperature at $30.6 \mathrm{GHz}$ for a co-evaporated BSCCO thin film $(3000 \AA)$ on $\mathrm{LaAlO}_{3}$. In (a) $\square$ represents the experimental data, + represents $\sigma_{1}$ obtained using the two-fluld model approximation, and the solid line represents a fit using the Bcs temperature dependence for $\sigma_{1}$.

substrate as a function of temperature. Since in this type of measurement the signal also interacts with the substrate, similar types of measurement were not performed with the film on $\mathrm{SrTiO}_{3}$ because of the extreme temperature sensitivity of its dielectric constant and loss tangent $[16,17]$. $\mathrm{LaAlO}_{3}$ has more stable properties and has proved to be a suitable substrate for microwave applications $[18,19]$. Observe that in the normal state $P$ decreases monotonically with temperature while $\Delta \theta$ remains almost constant. However, at the beginning of the normal-superconducting phase transition $(\sim 88 \mathrm{~K})$ both $P$ and $\Delta \theta$ decrease very quickly, levelling of at low temperatures. This behaviour is consistent with previous reports for BSCCO and YBCO thin films $[7,20,21]$.

The complex conductivity can be expressed in terms of the power transmission data according to the following relations [7], where $R$ and $I$ are the real and imaginary parts of the HTS thin film dispersion coeflicient and are related to $\sigma^{*}$ by $R=1+4 \pi \sigma_{2} / \omega \varepsilon$, and $l=4 \pi \sigma_{1} / \omega \varepsilon$, where $\omega / 2 \pi=f$ is the frequency of the wave and $\varepsilon$ is the relative dielectric constant of the HTs material. $P$ and $\theta$ were measured, and from these quantities $\sigma^{*}$ was calculated.

Figure 6 shows plots of $\sigma_{1}$ and $\sigma_{2}$ against temperature for the $\mathrm{BSCCO}$ film on $\mathrm{LaAlO}_{3}$. Observe that in the normal state $\sigma_{1}$ shows metallic behaviour, while $\sigma_{2}$ is close to zero as expected for a good conductor. When the superconducting transition begins (we refer to this temperature as $T_{\mathrm{c}}^{\mathrm{mw}}$, which in this case is $\sim 88 \mathrm{~K}$ ), both conductivities increase rapidly. As the temperature decreases, $\sigma_{1}$ increases to a maximum and then decreases quickly to the extent that we were unable to determine its value for temperatures below $\sim 74 \mathrm{~K}$, while $\sigma_{2}$ increased monotonically. This behaviour is consistent with that reported for YBCO and other BSCCO thin films $[7,20,21]$. The complex conductivity was determined to be $(2.0-\mathrm{j} 10) \times 10^{5} \mathrm{~S} \mathrm{~m}^{-1}$ at $77 \mathrm{~K}$. These values are approximately one order of magnitude larger than those obtained previously for BSCCO thin films on $\mathrm{LaAlO}_{3}$ at the same temperature and frequency [10]. The same temperature behaviour for $\sigma^{*}$ was observed for measurements at other frequencies within the Ka-band. From figure $6(a)$ it can be seen that the behaviour of $\sigma_{1}$ in the superconducting state does not follow that expected from the two-fluid model approximation [22] where,

$$
\sigma_{1}(T)=\sigma_{c}\left(T / T_{c}\right)^{4}
$$

and $\sigma_{\mathrm{c}}$ is the conductivity at $T_{\mathrm{c}}$. The measured data also deviated from $\sigma_{1}$ calculated using the BCs-based MattisBardeen equations [23]

$\sigma_{1}=\sigma_{\mathrm{c}}\left[2 \Delta\left(k_{\mathrm{B}} T\right)^{-1}\right] \exp \left[-\Delta / k_{\mathrm{B}} T\right] \ln (\Delta / \hbar \omega) \quad \hbar \omega \ll 2 \Delta$

where $k_{\mathrm{B}}$ is Boltzmann's constant, $\omega=2 \pi f$ is the angular frequency, and $\Delta$ is the energy gap.

The values of $\sigma_{2}$ can be used to determine $\lambda$ by using the expression $\lambda=\left(1 / \mu \omega \sigma_{2}\right)^{1 / 2}$, valid for homogeneous superconductors. $\lambda$ values of $\sim 1.97$ and $1.09 \mu \mathrm{m}$ at 77 and $20 \mathrm{~K}$ respectively, were obtained for the film on $\mathrm{LaAlO}_{3}$. The value of $\lambda$ at low temperature is less than that obtained in ion-beam-deposited BSCCO thin films on $\mathrm{MgO}(\lambda \sim 1.3 \mu \mathrm{m})$ [20], and compare well with those obtained using microstrip transmission lines fabricated with the same type of coevaporated BSCCO films used in this study $(\lambda(0) \sim 1.11$ $\mu \mathrm{m}$, where $\lambda(0)$ is the magnetic penetration depth at

$$
R=\frac{\left\{\left(2 n / P^{1 / 2}\right)\left[n \cos \left(k_{0} n t\right) \sin \left(k_{0} t+\theta\right)-\sin \left(k_{0} n t\right) \cos \left(k_{0} t+\theta\right)\right]-n\left(n^{2}-1\right) \sin \left(k_{0} n t\right) \cos \left(k_{0} n t\right)\right\}}{k_{0} d\left[n^{2} \cos ^{2}\left(k_{0} n t\right)+\sin ^{2}\left(k_{0} n t\right)\right]}
$$

and

$$
I=\frac{\left\{\left(2 n / P^{1 / 2}\right)\left[n \cos \left(k_{0} n t\right) \cos \left(k_{0} t+\theta\right)+\sin \left(k_{0} n t\right) \sin \left(k_{0} t+\theta\right)\right]-2 n^{2} \cos ^{2}\left(k_{0} n t\right)-\left(n^{2}+1\right) \sin ^{2}\left(k_{0} n t\right)\right\}}{k_{0} \mathrm{~d}\left[n^{2} \cos ^{2}\left(k_{0} n t\right)+\sin ^{2}\left(k_{0} n t\right)\right]}
$$


$T=0$ ) [24]. However, the values of $\lambda$ are still large when compared with those reported for BSCCO singlecrystals $(\lambda(0) \sim 0.3 \mu \mathrm{m})[25-27]$.

\subsection{Surface resistance measurements}

Cavity method The $R_{2}$ of the films was measured by monitoring the change in the quality factor $(Q)$ of a cylindrical, $\mathrm{TE}_{011}$ mode copper cavity, resonant at 58.9 $\mathbf{G H z}$, with one of its end walls replaced with the BSCCO thin film. Using an HP-8510B network analyser and Ginzton's impedance method the loaded $Q$ $\left(Q_{L}\right)$ of the cavity was determined by measuring the reflection coefficient. Knowing $Q_{L}$, the unloaded quality factor $\left(Q_{0}\right)$ of the cavity was obtained and the $R$, of the BSCCO films were computed by the method in [28]. As shown in Figure 7 , the $R_{3}$ of the BSCCO films decreased monotonically with temperature for $T / T_{c}>0.75$, levelling off at lower temperatures. Note that, except for very low temperatures, the $R_{1}$ for the film on $\mathrm{SrTiO}_{3}$ is less than that of its counterpart on $\mathrm{LaAlO}_{3}$. Values of $R_{8}$ of 865 and $376 \mathrm{~m} \Omega$ for the film on $\mathrm{SrTiO}_{3}$, and of 1391 and $370 \mathrm{~m} \Omega$ for the film on $\mathrm{LaAlO}_{3}$ were obtained at 77 and $20 \mathrm{~K}$ respectively. The $R_{a}$ values at low temperatures are almost one-fifth of those measured at lower frequencies on $\mathrm{BSCCO}$ films on $\mathrm{MgO}$ using microstrip and cavity resonator techniques $(\sim 25 \mathrm{~m} \Omega$ at $7 \mathrm{GHz}$ and $25 \mathrm{~K} ; R_{\mathrm{s}} \sim 1770 \mathrm{~m} \Omega$ at $58.9 \mathrm{GHz}$ assuming $R, \propto f^{2}$ dependence) [29]. They are also almost an order of magnitude less than those recently obtained by others from ring microstrip resonators fabricated on e-beam deposited $\mathrm{BSCCO}$ films on $\mathrm{MgO}$ ( $\sim 34 \mathrm{~m} \Omega$ at $4.2 \mathrm{~K}, 6 \mathrm{GHz}$, and $12 \mathrm{~dB} \mathrm{~m}$ incident $\mathrm{RF}$ power; $3276 \mathrm{~m} \Omega$ at $4.2 \mathrm{~K}, 58.9 \mathrm{GHz}$, using $R_{1} \propto f^{2}$ ) [30]. Since the $R_{a}$ of the film is larger than that of $\mathrm{Cu}$ for all temperatures (for very pure $\mathrm{Cu}$ and at $77 \mathrm{~K}$, $R_{\mathrm{s}} \sim 21.6 \mathrm{~m} \Omega$ at $58.9 \mathrm{GHz}$; the measured $R_{\mathrm{s}}$ value for a Cu sample at $77 \mathrm{~K}$ using the cavity was $\sim 45.4 \mathrm{~m} \Omega$ ) the flat part of the curve may be associated with residual losses in the film and not with limitations in the sensitivity of the cavity, in contrast to measurements of good qual ty YBCO thin films on $\mathrm{LaAlO}_{3}[7]$.

Linesir resonator method Microstrip transmission line resonators were fabricated and tested to examine the

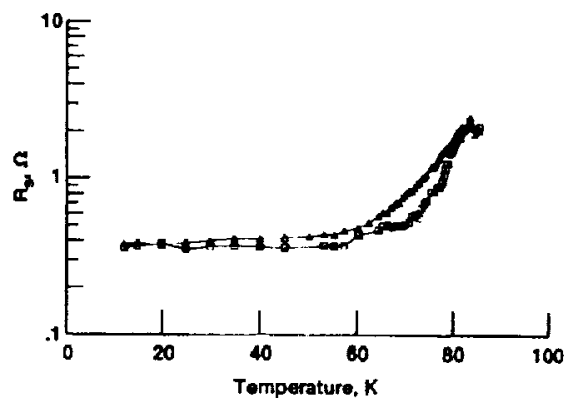

Flgure 7. Surface reslstance, $R_{8}$, at $58.9 \mathrm{GHz}$ against temperature for co-evaporated BSCCO thin films (3000 A) on $\mathrm{SrTiO}_{3}(\square)$ and $\mathrm{LaAlO}_{3}(\Delta)$.

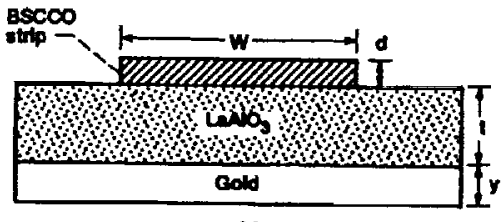

(4)

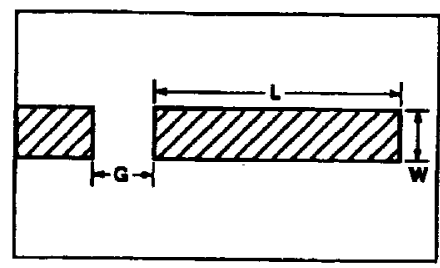

(9)

Floure 8. Cross section (a), and top view (b) of a BSCCO mlcrostrip transmission line resonator. For this resonator $W=300 \mu \mathrm{m}, L=7 \mathrm{~mm}, G=75 \mu \mathrm{m}, d=3000 \AA, t=0.010 \mathrm{in}$, and $y=1.5 \mu \mathrm{m}$. The calculated line impedance was $30 \Omega$.

losses of the BSCCO films in a structure that can be used in potential HTS passive microwave circuits such as filters, resonators or delay lines. The microstrip structure is shown in figure 8 and consisted of the BSCCO superconducting strip separated from a gold ground plane by the 0.010 in $\mathrm{LaAlO}_{3}$ substrate (figure $8(a)$ ). The strip width (W) was $300 \mu \mathrm{m}$ with a length $(L)$ of $7 \mathrm{~mm}$ (figure $8(b)$ ). This resulted in a $30 \Omega$ line impedance with the fundamental $(L=\lambda / 2)$ resonant frequency at 10.4 $\mathrm{GHz}$ and a second harmonic $(L=\lambda)$ at $20.2 \mathrm{GHz}$. The resonant strip was capacitively coupled to a $30 \Omega$ feed line by a $75 \mu \mathrm{m}$ wide gap (G). Transition from the coaxial test cables to the microstrip feed line was accomplished by a coaxial 'spark-plug' launcher.

The circuit was tested using an HP 8510B network analyser and a closed-cycle refrigerator for cooling. The test cable was calibrated up to the spark-plug launcher using coaxial open, short, and load standards. The calibration was performed at room temperature but was used at low temperatures as well since only minor shifts in the calibration with decreasing temperature were observed. The reflection coefficient $\left(S_{11}\right)$ was measured at temperatures from $\sim 20 \mathrm{~K}$ upwards, giving the loaded $Q$ of the circuit. Using the impedance method $[31,32]$ the unloaded $Q$ was extracted from the reflection data.

Figure 9 shows a plot of the unloaded $Q$ values against temperature for the superconducting and an identical gold ( $\mathrm{Au}$ ) resonator at 10.4 and $20.2 \mathrm{GHz}$. The $Q$ values of the Au resonator are relatively flat over this temperature range with the $Q$ values at $20.2 \mathrm{GHz}$ larger than those at $10.2 \mathrm{GHz}$, as expected for a conductor loss-limited transmission line resonator where $Q \propto f^{1 / 2}$, and $f$ is the frequency. A measurable response for the HTS resonators began just below the $T_{c}(R=0)$ value measured for the films. As seen in figure 9 , the $Q$ values increased with decreasing temperature and exceeded the $Q$ values of the $A u$ resonator around 60 to $65 \mathrm{~K}$. However, the BSCCO unloaded $Q$ values above $\sim 60 \mathrm{~K}$ 


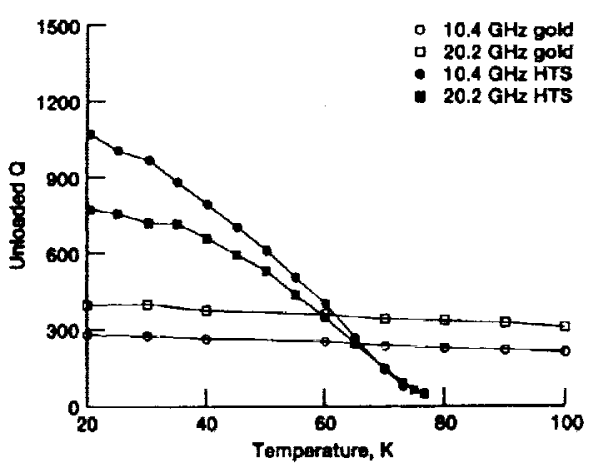

Flgure 8. Linear resonator unloaded $Q$ values for BSCCO HTS and gold strips.

are less than those for the Au resonator because the thinner BSCCO film $(0.3 \mu \mathrm{m}$ for BSCCO; $1.5 \mu \mathrm{m}$ for $A u)$ leads to overall higher conductor loss and lower $Q$. The $Q$ values of the superconducting resonator kept increasing down to the lowest temperatures measured, reaching values of approximately four times that of the Au circuit $Q$ at $10.4 \mathrm{GHz}$ and $20 \mathrm{~K}$, and approximately twice that of the Au circuit $Q$ at $20.2 \mathrm{GHz}$ and $20 \mathrm{~K}$. It should be noted that for the superconducting resonator the $10.4 \mathrm{GHz}$ resonance has a higher $Q$ than the 20.2 $\mathrm{GHz}$ resonance, contrary to the observations for the $\mathrm{Au}$ resonator. This is due to the $R_{3} \propto f^{2}$ dependence for the superconducting film which leads to $Q \propto 1 / f$ for a conductor loss-limited transmission line resonator.

The unloaded $Q$ values of the resonator may be used to estimate the $R$, of the BSCCO thin film [32]. The $R$, values obtained at 10.4 and $20.2 \mathrm{GHz}$, and the $R_{\mathrm{s}}$ values corresponding to Au are plotted in figure $10 . R$, values at $73 \mathrm{~K}$ of 13 and $22 \mathrm{~m} \Omega$ were obtained for the BSCCO at 10.4 and $20.2 \mathrm{GHz}$ respectively. At $20 \mathrm{~K}, R_{\mathrm{s}}$ was $\sim 0.75$ and $2.9 \mathrm{~m} \Omega$ at 10.4 and $20.2 \mathrm{GHz}$ respectively. These $R_{\mathbf{s}}$ values are less than those for the Au film at the same frequencies and temperatures, and are approx-

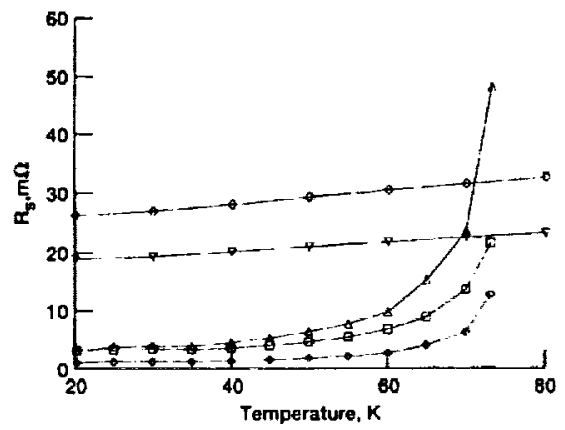

Flgure 10. Surface resistance, $R_{3}$, for BSCCO HTS strip at $10.4 \mathrm{GHz}(\diamond)$ and $20.2 \mathrm{GHz}(\square)$. The $R$, of a gold strip at $10.4(\nabla)$ and $20.2(O) \mathrm{GHz}$ are shown for comparison purposes. Also shown is the $R$, for the BSCCO HTS strip at $20.2 \mathrm{GHz}$ calculated from the measured $A_{8}$ at $10.4 \mathrm{GHz}$ assuming an $R_{\mathrm{s}} \propto f^{2}$ dependence $(\Delta)$. imately eight times smaller than earlier values $(\sim 25 \mathrm{~m} \Omega$ at $25 \mathrm{~K}$ ) reported at $7 \mathrm{GHz}$ [29]. Also plotted in figure 10 are the values of $R_{\mathrm{a}}$ for the BSCCO thin film at 20.2 GHz obtained assuming a $R_{\mathrm{s}} \propto f^{2}$ dependence, where $f$ is the frequency, and using the experimental values measured at $10.4 \mathrm{GHz}$. Note that although there is a noticeable discrepancy between the measured and calculated $R_{\text {s }}$ values at $20.2 \mathrm{GHz}$ at $T$ near $T_{\mathrm{c}}$, the agreement between the two sets of values improves at temperatures far below $T_{c}$.

\section{Dlscussion}

We have characterized co-evaporated BSCCO thin films on $\mathrm{SrTiO}_{3}$ and $\mathrm{LaAlO}_{3}$ substrates. We have compared the films in terms of their $T_{c}$ and $J_{c}$ values, surface morphology and XRD patterns. It was observed that, although both films have similar DC $T_{\varepsilon}$, the film on the $\mathrm{SrTiO}_{3}$ substrate has a larger $J_{\mathrm{c}}$ from 4.2 to $40 \mathrm{~K}$, a smoother surface morphology, and lower $R_{\mathrm{s}}$ than its counterpart on $\mathrm{LaAlO}_{3}$. From the power transmission measurements we have shown that the conductivity in the superconducting state does not follow either the BCS or two-fluid model temperature dependence. However, the observed increase in $\sigma_{1}$ for $T<T_{\mathrm{c}}$ is consistent with the observation of Ho et al [20] (for ion-beam-deposited BSCCO thin films on $\mathrm{MgO}$ at $60 \mathrm{GHz}$ ) who suggested that this trend below $T_{\mathrm{e}}$ is either an intrinsic temperature dependence of the homogeneous superconductor or the manifestation of the response of a composite consisting of superconducting regions growing in a normal conducting matrix. In the case of our films, although $\sigma_{1}$ increases very quickly upon cooling the sample below $\sim 88 \mathrm{~K}$, we also observed that, contrary to the observations by Ho et al [20], it reaches a maximum at $T$ not far below $T_{c}^{\mathrm{m} w}$ and then falls very quickly. This behaviour may be due to the better quality of the co-evaporated films under study as compared with those analysed by $\mathrm{Ho}$ et al [20], which have $T_{\mathrm{c}} \sim 68 \mathrm{~K}$ and $J_{\mathrm{c}} \sim 5 \times 10^{4} \mathrm{~A} \mathrm{~cm}^{-2}$ at $10 \mathrm{~K}$. Thus it may be reasonable to assume that as the quality of the material improves, i.e., as the normal conductor fraction in the material decreases, the behaviour below $T_{\mathrm{c}}$ could actually approach that expected from the two-fluid model. A more rigorous analysis should be performed along this line in the future.

From the $R$, values obtained using the resonant cavity technique, one can see that the values at $77 \mathrm{~K}$ for the films on $\mathrm{SrTiO}_{3}$ and $\mathrm{LaAlO}_{3}$ are approximately 12 and 20 times, respectively, larger than those of pure $\mathrm{Cu}$ and $A u$ at room temperature, and about 8 and 13 times, respectively, that of a Au-plated Cu sample. However, the $R_{s}$ measured at $10.4 \mathrm{GHz}$ using the linear resonator patterned on the film on $\mathrm{LaAlO}_{3}(\sim 13 \mathrm{~m} \Omega)$ is similar to that of pure $\mathrm{Cu}$ and pure $\mathrm{Au}$ at the same frequency and temperature $\left(R_{\mathrm{s}, \mathrm{Cu}} \sim 10 \mathrm{~m} \Omega, R_{\mathrm{s}, \mathrm{Au}} \sim 14.3 \mathrm{~m} \Omega\right)$, and lower than that of its $A u$ counterpart $(\sim 23 \mathrm{~m} \Omega)$. We 
found that when the $R_{3} \propto f^{2}$ dependence was used to determine the $R$, of the BSCCO film at $20.2 \mathrm{GHz}$ using the resonator technique, the agreement between the calculated and measured values at this frequency improved for temperatures far from $T_{c}$. However, when the same approach was used to determine the $R_{3}$ at $58.9 \mathrm{GHz}$ $\left(R_{1} \sim 13 \mathrm{~m} \Omega\right.$ at $10.4 \mathrm{GHz}$, and $\sim 417 \mathrm{~m} \Omega$ at $\left.58.9 \mathrm{GHz}\right)$ the resulting value was approximately one-third of that obtained by the cavity technique at temperatures near $77 \mathrm{~K}$, the discrepancy becoming worse for lower temperatures. This deviation is not unexpected since we are dealing with an heterogeneous system in which the different components (superconducting, normal and possibly insulating) do not necessarily respond to frequency changes in the same way and therefore may alter the frequency dependence of the microwave losses that one expects for a homogeneous superconductor. In addition it will be interesting to see how the different measurement techniques contribute to the deviation especially when it has been suggested by others that calibration differences in different techniques to measure $R$, can contribute to the lack of correlation between $R$, values in HTs thin films [33].

We have also obtained $\lambda$ for the BSCCO films under discussion. Low temperature values for $\lambda \sim 1.0 \mu \mathrm{m}$ were obtained. Although these values compare favourably with those obtained by others in BSCCO films, they are still approximately three times the values reported by others for BSCCO single crystals. This may be due to the inhomogeneity of the films under study as shown by the unknown peaks observed in the XRD pattern (figure 3). It has been shown by others that nonsuperconducting inclusions and weak link effects result in an increase of $\lambda[34]$. The fact that the low temperature $\lambda$ is large compared with the values typically obtained at low temperatures for YBCO thin films $(\sim 0.14-0.3 \mu \mathrm{m})$ [5-7] may impose limitations in the use of this type of BSCCO thin film for microwave applications. In normal conductors, in order to have low conductor losses, the conductor thickness must be at least three times larger than the normal skin depth $(\delta)$. If, as in the YBCO films, the superconducting properties of the BSCCO films deteriorate as the film thickness goes beyond $0.5 \mu \mathrm{m}$, then it is clear that improvements in the BSCCO film growth are still necessary. Therefore careful study of the various microwave transmission lines, in terms of the contribution to total losses (i.e., conductor, substrate and radiation losses [35]) must be performed to determine, in view of the limitations described above, for which of these structures the BSCCO HTs film would be more suitable.

Nevertheless, since the values of $T_{c}$ and $J_{c}$ compared well with those of other BSCCO thin films deposited by other techniques, we believe that the microwave data presented here are representative of state-of-the-art BSCCO films. In view of this we can see that this type of film offers some possibilities for microwave applications at low frequencies (i.e., $\leqslant 20 \mathrm{GHz}$ ), but potential applications at frequencies around $60 \mathrm{GHz}$ and above will require further improvements in the material.

\section{Conclusions}

We have characterized co-evaporated BSCCO thin films on $\mathrm{SrTiO}_{3}$ and $\mathrm{LaAlO}_{3}$. The $J_{c}$ values measured for these films are better than or eqqual to those reported by others for state-of-the-art BSCCO films deposited by other techniques. From the microwave power transmission measurements we were able to determine $\sigma^{*}$; it was found that the temperature dependence of $\sigma^{*}$ for $T<T_{\mathrm{s}}$ deviates from both the BCs theory and the two-fluid model. The low temperature values of $\lambda$ agreed with those reported by others for BSCCO films, but were approximately three times larger than those of BSCCO single crystals. $R$, values for the BSCCO thin films were measured at $10.4,20.2$, and $58.9 \mathrm{GHz}$. From the $R_{\text {s }}$ data it is evident that the low- $T_{c}$ phase BSCCO thin films could offer possibilities for microwave applications at low frequencies ( $\leqslant 20 \mathrm{GHz}$ ), but applications at frequencies around $60 \mathrm{GHz}$ and above will require further improvements in the material. To our knowledge this is the first time a microwave characterization in terms of the transport parameters most relevant for transmission line applications has been performed on the same BSCCO film and in the frequency range from 10 to 60 GHz.

\section{Acknowledgments}

The authors would like to thank Ms Ruth Cipcic and Mr Ralph Garlick for the x-ray-diffraction measurements. The assistance of D Bohmann in obtaining the SEM micrographs of the films and measuring their thickness is deeply appreciated. We thank Ms C Cubbage for her assistance in measurements of the gold linear resonator. Finally we thank Dr V O Heinen for helpful discussions and suggestions.

This paper is declared a work of the US Government and is not subject to copyright protection in the United States of America.

\section{Aelerences}

[1] Klein N, Muller G, Piel H, Roas B, Schultz L, Klein U and Peiniger M 1989 Appl. Phys. Lett. 54757

[2] Drabeck L, Gruner G, Chang J J, Inam A, Wu X D, Nazar L, Venkatesan T and Scalapino D J 1989 Phys. Rev. B $\mathbf{4 0} 7350$

[3] Harshman D R, Schneemeyer L F, Waszczak J V, Aeppli G, Cava R J, Batlogg B, Rupp L W, Ansaldo E J and Williams D L 1989 Phys. Rev. B 39851

[4] Qui X G, Cui C G, Zhang Y Z, Li S L, Zhao Y Y, Xu P and Li L 1990 J. Appl. Phys. 68884

[5] Anlage S M, Langley B W, Deutscher G, Halbritter J and Beasley M R 1991 J. Phys. Rev. B 449764

[6] Kobrin P H, Ho W, Hall W F, Hood P J, Gergis I S and Harker A B 1990 Phys. Rev. B 426259

[7] Miranda F A, Gordon W L, Bhasin K B, Heinen V O and Warner J D $1991 \mathrm{~J}$. Appl. Phys. 705450 
[8] Maeda H, Tanaka Y, Fukutomi M and Asano T 1988 Japan. J. Appl. Phys. 27 L209

[9] Talvacchio J, Wagner G R and Talisa S H 1991 Microwave J. 34105

[10] Miranda F A, Bhasin K B, Heinen V O, Kwor R and Kalkur T S 1990 Physica C 16891

[11] Kalkur T S, Kwor R Y, Jernigan S and Smith R 1989 Science and Technology of Thin Film Superconductors ed R D McConnell and S A Wolf (New York: Plenum) p 487

[12] Narumi E, Lee J, Li C, Hosokawa S, Patel S and Shaw D T 1991 Appl. Phys. Lett. 593180

[13] Xi XX et al 1991 IEEE Trans. Magn. MAG-27 982

[14] Yeh J J and Hong M 1989 Appl. Phys. Lett. 54769

[15] Bean C P 1962 Phys. Rev. Lett. 8250

[16] Gorshunov B P, Kozlov G V, Krasnosvobodtsev S I, Pechen E V, Prokhorov A M, Prokhorov A S, Syrotynsky O I and Volkov A A $1988^{\circ}$ Physica C $153-154667$

[17] Weaver H E 1959 J. Phys. Chem. Solids 11274

[18] Miranda F A, Gordon W L, Bhasin K B, Ebihara B T, Heinen V O and Chorey C M 1990 Microwave Opt. Tech. Lett. 311

[19] Simon R W, Platt C E, Lee A E, Lee G S, Daly K P, Wire M S, Luine J A and Urbanik M $1988 \mathrm{Appl}$. Phys. Lett. $\mathbf{5 3} 2677$

[20] Ho W, Hood P J, Hall W F, Kobrin P, Harker A B and DeWames R E 1988 Phys. Rev. B 387029

[21] Kobrin P H, Ho W, Hall W F, Hood P J, Gergis I S and Harker A B 1990 Phys. Rev. B 426259

[22] Hinken J H 1989 Superconductor Electronics: Fundamentals and Microwave Applications (Berlin: Springer)
[23] Tinkham M 1980 Introduction to Superconductivity (New York: McGraw-Hill)

[24] Byrne D P, Kwor R Y and Kalkur T S 1991 J. Appl. Phys. 696693

[25] Mitra S, Cho J H, Lee W C, Johnston D C and Kogan V G 1989 Phys. Rev. B 402674

[26] Gygax S, Xing W, Rajora O and Curzon A 1989 Physica C 162-164 155

[27] Ansaldo E J, Batlogg B, Cava R J, Harshman D R, Rupp L W, Riseman T M and Williams D 1989 Physica C 162-164 259

[28] Miranda F A, Gordon W L, Bhasin K B and Warner J D 1990 Appl. Phys. Lett. 571058

[29] Lichtenberg C L, Wosik J, Davis M and Wolfe J C 1989 NASA TM-J02I59

[30] Andreone A, Attanasio C, Dichiara A, Maritato L, Nigro A, Peluso G and Vaglio R 1991 Physica C 180 272

[31] Ginzton E L 1957 Microwave Measurements (New York: McGraw-Hill)

[32] Chorey C M, Kong K S, Bhasin K B, Warner J D and Itoh T 1991 IEEE Trans. Microwave Theory Tech. 391480

[33] Talvacchio J and Wagner G R 1990 SPIE Proc. 1292

[34] Hylton T L, Kapitulnik A, Beasly M R, Carini J P, Drabeck L and Gruner G 1988 Appl. Phys. Lett. 53 1343

[35] Kong K S, Bhasin K B and Itoh T 1991 SPIE Proc. 147757 


\title{
PROCESSING, ELECTRICAL AND MICROWAVE PROPERTIES OF SPUTTERED Tl-Ca-Ba-Cu-O SUPERCONDUCTING THIN FILMS
}

\author{
G. Subramanyam and V. J. Kapoor \\ Department of Electrical \& Computer Engineering \\ University of Cincinnati \\ Cincinnati, OH 45221-0030 \\ C. M. Chorey \\ Sverdrup Technology Inc. (NASA Lewis Group) \\ Cleveland, OH 44135 \\ K. B. Bhasin \\ NASA Lewis Research Center \\ Cleveland, OH 44135
}

\begin{abstract}
A reproducible fabrication process has been established for $\mathrm{TlCaBaCuO}$ thin films on $\mathrm{LaAJO}_{3}$ substrates by if magnetron sputtering and post-deposition processing methods. Electrical transport properties of the thin films were measured on patterned four-probe test devices. Microwave properties of the films were obtained from unloaded $Q$ measurements of all-superconducting ring resonators. This paper describes the processing, electrical and microwave properties of $\mathrm{Tl}_{2} \mathrm{Ca}_{1} \mathrm{Ba}_{2} \mathrm{Cu}_{2} \mathrm{O}_{x}$ (2122) phase thin films.
\end{abstract}

\section{I.INTRODUCTION}

The high temperature superconducting thin films show great promise for electronic applications at $77^{\circ} \mathrm{K}$. Since the discover, of bigh $T_{c}$ materials, there has been a substantial progress in the applications such as SQUIDs, passive microwave devices, IR detectors and interconnections in microelectronics. Among the high $T_{c}$ materials, the TICaBaCuO compound bas proven to possess the highest $T_{c}$ of $125^{\circ} \mathrm{K}[1]$, and beoce offers a wide margin of temperature range for applications at $77^{\circ} \mathrm{K}$. Thin films of $\mathrm{TICaBaCuO}$ compound have shown $T_{c}$ as high as $120^{\circ} \mathrm{K}$, and critical current density $\left(J_{c}\right)$ greater than $10^{6} \mathrm{~A} / \mathrm{cm}^{2}$ at $77 \mathrm{~K}[2]$. Also, $\mathrm{TlCaBaCuO}$ thin films, primarily of 2122 phase have shown surface resistance $\left(R_{s}\right)$ about 80 times lower than $\mathrm{Cu}$ at 10 $\mathrm{GHz}$ and $77^{\circ} \mathrm{K}[3]$. This research work primarily addresses a reproducible processing method for $\mathrm{TlCaBaCuO}$ thin films of 2122 phase, electrical transport measurements and also microwave ring resonator measurements.

This research was supported by NASA Lewis Research Center. Manuscript received August 24, 1992.

\section{II.PROCESSING OF TICaBaCuO THIN FILMS}

The TICaBaCuO thin films were sputter deposited on (100) $\mathrm{LaAlO}_{3}$ substrates from a single composite powder target in a CVC model 601 if magnetron sputtering system: The target was a $\mathrm{Tl}$ enriched $\mathrm{Tl}_{2} \mathrm{C}_{3} \mathrm{Ba}_{2} \mathrm{Cu}_{3} \mathrm{O}_{x}$ (2223) powder target, with $20 \%$ excess $\mathrm{T}_{2} \mathrm{O}_{3}$ to compensate for the loss of Tl during post-processing steps and to maintain sufficient composition for several deposition runs. The sputter depositions were performed at an if power density of 0.7 $W / \mathrm{cm}^{2}$, and the chamber pressure at $5 \mathrm{mTorr}$, in a pure argon atmosphere. The thin films were deposited at a deposition rate of approximately $30 \mathrm{~A} / \mathrm{min}$. The sputter deposited thin films of 0.3-0.5 $\mu \mathrm{m}$ thickness were post-processed in two steps: first, sintering in air at $850^{\circ} \mathrm{C}$ for $12-15$ minutes in an optimum $\mathrm{Tl}_{2} \mathrm{O}$ partial pressure, and the second, annealing in oxygen flow at $750^{\circ} \mathrm{C}$. These steps were performed in a box furnace with samples placed in an enclosed platinum crucible. The $\mathrm{Tl}_{2} \mathrm{O}$ partial pressure was provided by placing 2223 pellets inside the crucible. Both the steps were performed with the same aumber of pellets placed inside the crucible. The $\mathrm{Tl}_{2} \mathrm{O}$ partial pressure provided during the sintering process establishes the phase in the thin films. The details of the post-processing steps bave been reported earlier[4-5].

To provide the optimum $\mathrm{Tl}_{2} \mathrm{O}$ partial pressure during the post-processing steps, a simple lechnique was used to monitor the reduction in $\mathrm{II}$ content in the as-deposited thin films, after each sputtering run. Percentage reduction in $\mathrm{Tl}$ content from nun to run was obcained by Auger Electron Spectroscopy(AES) surface analysis on the as-deposited samples. This percentage reduction in $\mathrm{Tl}$ gives an approximate estimale of additional $\mathrm{TI}_{2} \mathrm{O}$ partial pressure needed for the post-deposition processes. The estimated additional $\mathrm{Tl}_{2} \mathrm{O}$ partial pressure was provided

O 1993 IEEE. Reprinted, with permission, from IEEE Transactions on Applied Superconductivity, vol. 3. no. 1. Mar. 1993. pp. 1749-1752. 
by adding additional 2223 pellets in the crucible. This technique has yielded reproducible high $T_{c}$ and high $J_{c}$ thin films. The annealed thin films were essentially smooth in morphology. The superconducting thin films were characterized by $X$-ray diffraction(XRD) analysis to determine the phase purity. XRD spectra obtained on a TICaBaCuO thin film is shown in figure 1 . The characteristic peaks of 2122 and 2223 phases were present. The 2122 phase with $c$-axis oriented growth was the dominant phase in the thin films, as determined from the XRD data.

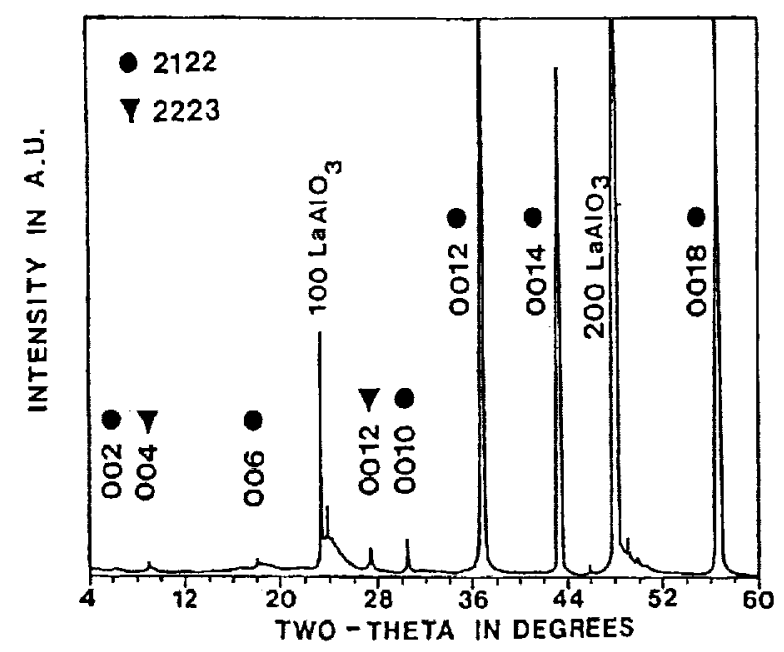

Fig.1 XRD spectra obtained on an annealed TlCaBaCuO thin film showing c-axis oriented 2122 and 2223 peaks.

\section{III.ELECTRICAL TRANSPORT PROPERTIES}

Electrical transpor measurements were performed on patterned four-probe test devices 10,25 and $50 \mu \mathrm{m}$ wide, and $1 \mathrm{~mm}$ long. The test devices were patterned on as-deposited TICaBaCuO thin films using standard positive photoresist photo-lithography, and wet chemical etching in a weak phosphoric acid. Positive photoresist AZ 1421 was used for the photo-lithography. The etching solution was a 1:100 phosphoric acid:DI $\mathrm{H}_{2} \mathrm{O}$ heated to about $75^{\circ} \mathrm{C}$. The etch rate was approximately $30 \mathrm{~d} / \mathrm{min}$. The patterned samples were post-processed using our standard procedures described above.

For reliable electrical measurements, a process for making low resistance gold contacts on TICaBaCuO thin films was established. First, metal bonding pads were formed by thermally evaporating $6000 \dot{A}$ thick gold film on the superconducting pads of the four-probe device. The samples were annealed at $600^{\circ} \mathrm{C}$ for 15 minutes in an oxygen flow of 1 liter/min, followed by a slow fumace cooling for 30 minutes after the furnace was switched off. Gold wires were bonded to the pads using an ultrasonic wedge bonder. Typically, the four-probe test devices showed zero resistance $T_{c}$ between 97 and $100^{\circ} \mathrm{K}$. The measurements were performed at a constant applied current of $10 \mu \mathrm{A}$. The contact resistance obtained from the I-V measurements of the four-probe devices is typically a few $\mathrm{mll}$ at temperatures below Tc. The specific contact resistivity was approximately $3.65 \times 10^{-5} \Omega-\mathrm{cm}^{2}$ at 90 ${ }^{\circ} \mathrm{K}$, and below $10^{8} \mathrm{0 \textrm {cm } ^ { 2 }}$ at $77^{\circ} \mathrm{K}$.

The zero-field transport current density $\left(J_{c}\right)$ measurements were performed using dc and pulsed curreat techniques, using a $1 \mu \mathrm{V} / \mathrm{mm}$ electric field criterion. Figure 2 shows the $J_{c}$ vs temperature measuremeots obtained on two four probe test devices. Zero-field $J_{c}$ greater than $10^{5} \mathrm{~A} / \mathrm{cm}^{2}$ at $77^{\circ} \mathrm{K}$ was obtained in the four-probe devices tested.

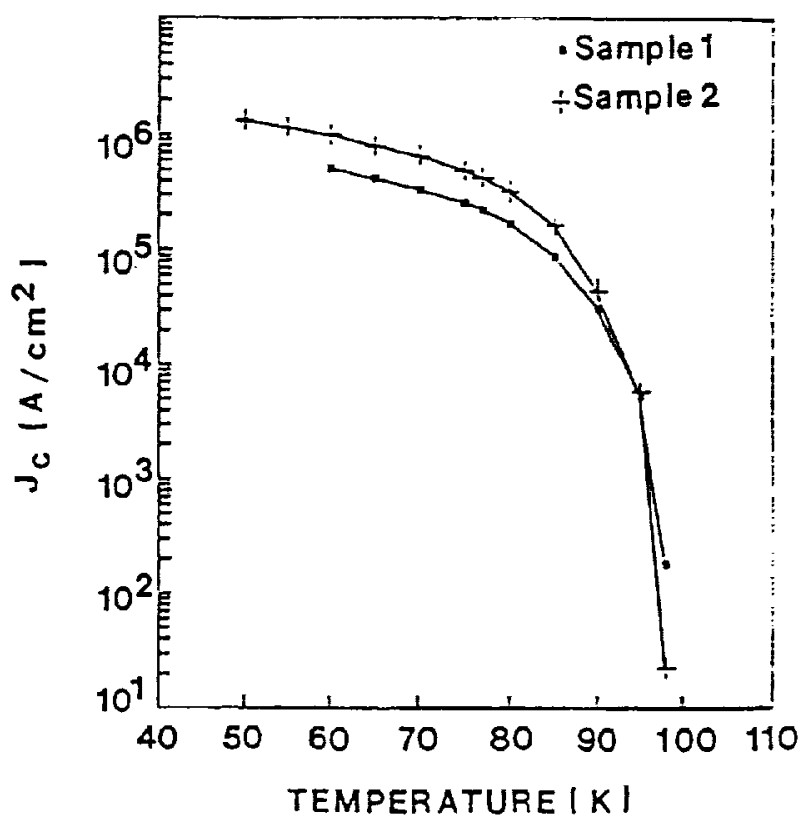

Fig.2 Zero-field $J_{c}$ vs Temperature for two differeat $\mathrm{TlCaBaCuO}$ thin films measured using I $\mu \mathrm{V} / \mathrm{mm}$ criterion.

\section{III.MICROWAVE PROPERTIES}

The microwave properties of the $\mathrm{TICaBaCuO}$ thin films were obtained indirectly by measuring the unloaded $Q$ of allsuperconducting ring resonators. A ring resonator was designed for a fundamental resonance at $12 \mathrm{GHz}$. The device consisted of a ring structure separated from the feed line by a small coupling gap. The figure 3 shows a ring resonator designed for fundamental resonance at $12 \mathrm{GHz}$, for $10 \mathrm{mil}$ 
thick $\mathrm{LaAlO}_{3}$ substrates $\left(\epsilon_{\mathrm{r}}=24.5\right)$. In the figure, the linewidth of the ring and the microstrip feed line is $W=5.6$ mils, the coupling gap $G=1.75$ mils, and the mean radius of the ring $R=77$ mils.

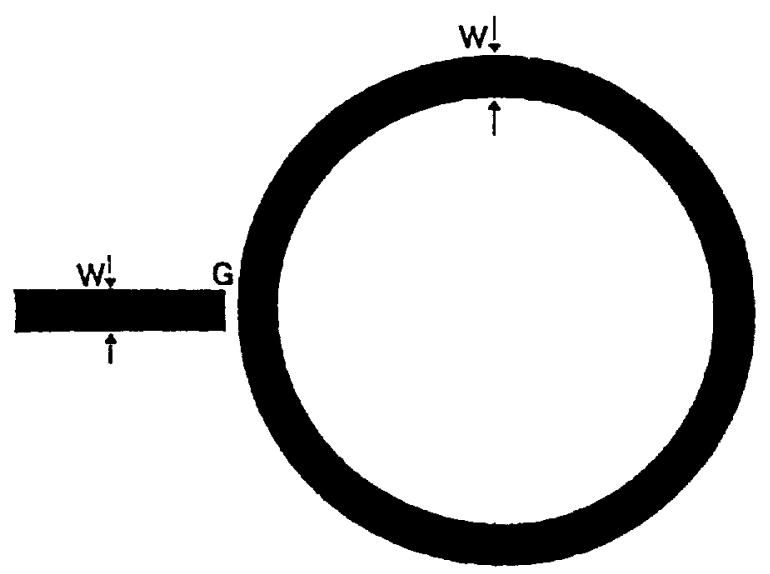

Fig.3 Mirrostrip ring resonator designed for $12 \mathrm{GHz}$

The $\mathrm{TICaBaCuO}$ ring resonators were fabricated by patterning $0.3 \mu \mathrm{m}$ thin films using AZ 1421 photolithography, and wet chemical etching techniques described before. After processing the top conductor side, the ground plane TlCaBaCuO thin film was deposited to a thickness of $0.3 \mu \mathrm{m}$, and post-processed using the same steps described in section II. The unloaded $Q$ of the resonators were obtained by swept frequency reflection measurements[6] using a HP8720B network analyser. The unloaded $Q$ versus temperature abaracteristics for an all-superconducting $\Pi \mathrm{CaBaCuO}$ ring resonator is shown in curve $A$ of figure 4. For comparison, data for a gold resonator with gold ground plane is shown in curve $B$.

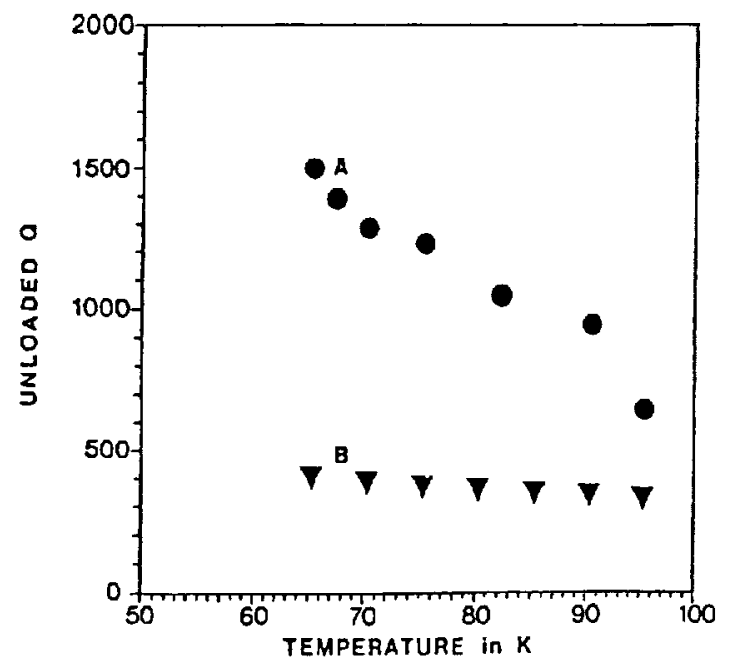

Fig.4 The unloaded $Q$ vs temperature characieristics of an all-superconducting $\mathrm{TlCaBaCuO}$ ring resonator
The unloaded $Q$ of the superconducting ring resonator is approximately four times higher than the gold resonator at 65 ${ }^{\circ} \mathrm{K}$. The ring resonators offer an indirect method for measuring the surface resistance $\left(R_{2}\right)$ of superconducting thin films. By separating the conductor and dielectric losses, the $R_{\text {s }}$ of the $77 \mathrm{CaBaCuO}$ thin films were calculated using the standard microstrip loss equations described by Pucel et al[7]. The effective $\mathrm{R}_{\text {, at }} 12 \mathrm{GHz}$ and $77^{\circ} \mathrm{K}$ was determined to be typically between 1.5 and $2.75 \mathrm{mn}$, almost an order of magnitude lower than the $R_{3}$ of $\mathrm{Cu}$ at the same frequency and temperature. The lowest surface resistance reported in $\mathrm{Tl}_{2} \mathrm{Ca}_{1} \mathrm{Ba}_{2} \mathrm{Cu}_{2} \mathrm{O}_{x}$ thin films to date is $0.130 \mathrm{~m} n$ at $77 \mathrm{~K}$ and $10 \mathrm{GHz}[3]$.

The swept frequency reflection measurements performed at several temperatures, were also used in determining the effective penetration depth in the $\mathrm{TC} \mathrm{CaBaCuO}$ thin films. The shift in resonance frequency with temperature is mainly due to the temperature dependence of the penetration depth in the superconducting thin film. The phase velocity of a superconducting microstrip line with 2 superconducting ground plane is given by[8],

$$
v_{p h}=c N \epsilon_{e f f}\{1+2(\lambda / h) \operatorname{coth}(t / \lambda)\}^{-0.5}-(1)
$$

where $c$ is the velocity of light, $\epsilon_{\text {eff }}$ is the effective dielectric constant, $b$ is the substrate thickness, $t$ is the thickness of the microstrip, $\lambda$ the penetration depth of the superconducting microstrip. The penetration depth is temperature dependent based on the Gorter-Casimir relationship, ie.,

$$
\lambda(T)=\lambda(0)\left[1-(T / T c)^{4}\right]^{-0.5}
$$

for temperature $T$ less than $T c, \lambda(0)$ is the penetration depth at $\mathrm{T}=0^{\circ} \mathrm{K}$. The resonance frequency of the ring resonator is given by the equation

$$
\mathrm{f}=\mathrm{nv}_{\mathrm{ph}} /(2 \mathrm{~L})
$$

where $f$ is in $\mathrm{GHz}, \mathrm{L}$ is the mean circumference of the ring in $\mathrm{mm}$, and $\mathrm{n}$ is the integer order of resonance. From the above equations, the lowest value of the effective $\lambda(0)$ was determined to be $6890 \AA$. The typical value ranges between $7000 \AA$ and $8000 \AA$. Since the thin films were only $0.3-0.4$ $\mu \mathrm{m}$ thick, the penetration depth depends upon the properties of the superconductor through the entire film. This may be a reason for the higher penetration depth. The typical values of penetration depth reported in literature is between 4000 and $8000 \dot{A}$ ip Tl 2122 phase thin films[9-10]. The higher value of penetration deptb is also an indication of the film quality. Improvements in film quality should yield lower effective 
penetration depth and lower $R$, values.

\section{IV.SUMMARY}

A reproducible fabrication process has been established for $\mathrm{TCaBaCuO}$ thin films of 2122 phase on $\mathrm{LaANO}_{3}$ substrates. Zero resistance $T_{c}$ as high as $100^{\circ} \mathrm{K}$, and the zero-field $J_{c}$ as high as $5 \times 10^{5} \mathrm{~A} / \mathrm{cm}^{2}$ were obtained in fourprobe test devices. The surface resistance of the $\mathrm{TICaBaCuO}$ thin films obtained by separating the conductor losses from $Q$ measurements in ring resonators is typically between 1.5 and $2.75 \mathrm{~m} \Omega$ at $12 \mathrm{GHz}$ and $77^{\circ} \mathrm{K}$. The effective penetration depth at $0^{\circ} \mathrm{K}$, calculated from the resonance frequency shift with temperature measurements was typically between 7000 and $8000 \dot{A}$.

\section{REFERENCES}

[1] S. S. P. Parkin, V. Y. Lee, E. M. Engler, A. I. Nazzal, T. C. Huang, G. Gorman, R. Savoy and R. Beyers,"Bulk superconductivity at $125^{\circ} \mathrm{K}$ in $\mathrm{Tl}_{2} \mathrm{Ca}_{2} \mathrm{Ba}_{2} \mathrm{Cu}_{3} \mathrm{O}_{\mathrm{x}}{ }^{*}$, Phys. Rev. Lett., vol.60, pP 2539-42, 1988.

[2] W. Y. Lee, S. M. Garrison, M. Kawasaki, E. I. Venturini, B. T. Ahn, R. Boyers, J. Salem, R. Savoy, and J. Vasquez, "Low temperature formation of epitaxial $\mathrm{Tl}_{2} \mathrm{Ca}_{2} \mathrm{Ba}_{2} \mathrm{Cu}_{3} \mathrm{O}_{10}$ thin films in reduced $\mathrm{O}_{2}$ pressure", Appl. Phys. Lett., vol.60, pp 772774, 1992.

[3] W. L. Holstein, L. A. Parisi, C. Wilker, and R. B. Flippen, " $\mathrm{Tl}_{2} \mathrm{Ba}_{2} \mathrm{Ca}_{1} \mathrm{Cu}_{2} \mathrm{O}_{8}$ films with very low microwave surface resistance up to $95 \mathrm{~K}^{*}$, Appl. Phys. Lett., vol.60, pp 2014-2016, 1992.

[4] D. S. Ginley, J. F. Kwak, E. L. Venturini, B. Morosin, and R. J. Baughman, "Morphology control and high critical currents in superconducting thin films in the $71 \mathrm{CaBaCuO}$ system", Physica $C_{\text {, }}$ vol.160, pp 42-48, 1989.

[5] G. Subramanyam, F. Radpour, V. J. Kapoor, and G. H. Lemon, "Fabrication and chemical composition of If magnetron sputtered $\mathrm{TlCaBaCuO}$ high $\mathrm{Tc}$ thin films", J. Appl. Phys. vol.68, pp 1157-63, 1990.

[6] J. Aikken, "Swept frequency microwave $Q$ factor measurements", Proc. of Inst. Elec. Eng. vol.123, pp 855-862, 1976.

[7] R. A. Pucel, D. J. Masse, and C. P. Hartwig, "Losses in microstrip", IEEE Trans. Microwave Theory Tech., vol.16, pp 342-350, 1968. Also "Correction to losses in microstrip", IEEE Microwave Theory Tech., vol.16, pp 1064, 1968.

[8] R. L. Kautz, "Picosecond pulses on superconducting strips", J. Appl. Phys. vol.49, pp 308-314, 1978.

[9] V. M. Hietala, J. S. Martens, D. S. Ginley, T. E. Zipperian, C. P. Tigges, M. S. Housel, and T. A. Plut, "Evaluation of superconducting Tl-Ca-Ba-Cu-O thin film surface resistance using a microstrip ring resonator", IEEE Microwave and Guided Wave Lett., vol.1, pp 84-86, 1991.

[10] Private Communications with Dr. Felix A. Miranda of NASA Lewis Research Center. 


\title{
Electrical-transport properties and microwave device performance of sputtered TICaBaCuO superconducting thin films
}

\author{
G. Subramanyam and V. J. Kapoor \\ of Cincinnati, Cincinnati, Ohio $45221-0030$ \\ C. M. Chorey \\ Suerdrup Technology Inc., NASA Lewis Group, Cleveland, Ohio 44135 \\ K. B. Bhasin \\ NASA Lewis Research Center, Cleveland, Ohio 44135
}

Microwave Electronics Laboratory, Department of Electrical and Computer Engineering, University

(Received 21 February 1991; accepted for publication 1 June 1992)

Tl-Ca-Ba-Cu-O high-temperature superconducting thin films were deposited on lanthanum aluminate substrates, by if magnetron sputtering and postannealing methods. A reproducible fabrication process with low-resistance metal contacts has been established for high- $T_{c}$ and high $J_{c}$ TlCaBaCuO thin films after patterning using standard microelectronic photolithography and wet chemical etching techniques. Low-resistance gold contacts on TlCaBaCuO thin films were obtained by annealing in an oxygen flow of $11 / \mathrm{min}$ followed by a slow furnace cooling. Specific contact resistivity was approximately $10^{-10} \Omega \mathrm{cm}^{2}$ below $77 \mathrm{~K}$. High transition temperatures as high as $100 \mathrm{~K}$, and current density at zero magnetic field greater than $10^{5}$ $\mathrm{A} / \mathrm{cm}^{2}$ are routinely obtained in $0.3-0.5 \mu \mathrm{m}$ TICaBaCuO thin films. The morphology studies of the films using scanning electron microscopy show the correlation between $J_{c}$ and the microstructure of the films. Films with featureless morphology have larger zero-field transport currents. The microwave properties of $\mathrm{TlCaBaCuO}$ thin films were investigated by designing, fabricating, and characterizing microstrip ring resonators with a fundamental resonance frequency of $12 \mathrm{GHz}$ on 10 -mil-thick lanthanum aluminate $\left(\mathrm{LaAlO}_{3}\right)$ substrates. Ring resonators with a superconducting ground plane of $0.3 \mu \mathrm{m}$ thickness and a gold ground plane of $1 \mu \mathrm{m}$ thickness were fabricated and characterized in the temperature range of 60-95 K. Typical unloaded quality factors $Q$ for the ring resonators at $12 \mathrm{GHz}$ were above 1500 at $65 \mathrm{~K}$, compared to an unloaded $Q$ of 370 for a gold ring resonator. A surface resistance as low as 1.5 $\mathrm{m} \Omega$ at $12 \mathrm{GHz}$ and $77 \mathrm{~K}$ was obtained in $0.3 \mu \mathrm{m} \mathrm{TlCaBaCuO}$ thin films using the ring resonator $Q$ measurements. Typical values of penetration depth at $0 \mathrm{~K}$ in the $\mathrm{TlCaBaCuO}$ thin films were determined to be between 7000 and $8000 \AA$ using the temperature variation of resonance frequency measurements.

\section{INTRODUCTION}

Since the discovery of a copper-oxide high transition emperature $\left(T_{c}\right)$ superconductor by Bednorz and Muller in January 1986,' there has been substantial progress in superconducting electronics. Several new compounds such as $\mathrm{YBaCuO},{ }^{2} \mathrm{BiSrCaCuO},{ }^{3}$ and $\mathrm{TlCaBaCuO}$ (Ref. 4) have been found to be superconducting above $90 \mathrm{~K}$, thus making it feasible for electronic applications at liquid-nitrogen temperature $(77 \mathrm{~K})$. Currently, worldwide research is underway for developing high- $T_{c}$ superconducting electronics. Already rapid progress has been made for applications of high- $T_{c}$ materials in areas such as superconducting quantum interference devices (SQUIDs), passive microwave devices, $I R$ detectors, and interconnections in microelectronics. ${ }^{\text {s-8 }}$

Among the high- $T_{c}$ materials, the $\mathrm{TCaBaCuO}$ compound has proven to possess the highest $T_{c}{ }^{9}$ which means a wide margin of operational range is available for electronic applications at $77 \mathrm{~K}$. The $\mathrm{TlCaBaCuO}$ thin films are very attractive for electronic applications, as they have shown high $T_{c}$ and high critical current density $J_{c}{ }^{10,11}$ Fabrication of $\mathrm{TICaBaCuO}$ thin films on lanthanum alu- minate $\left(\mathrm{LaAlO}_{3}\right)$ substrates has been reported by the authors. ${ }^{12-14} \mathrm{LaAlO}_{3}$ substrates have a good $a$-axis lattice match with TlCaBaCuO thin films to permit highly $c$-axisoriented growth of $\mathrm{TlCaBaCuO}$ superconducting thin films. The dielectric constant of $\mathrm{LaAlO}_{3}$ is 24.5 (Ref. 15) and the loss tangent is approximately $8.3 \times 10^{-9}$ at $77 \mathrm{~K} .^{15}$ The growth of $\mathrm{TlCaBaCuO}$ thin films on $\mathrm{LaAlO}_{3}$ substrates offers promising applications in the area of microwave electronics. The only disadvantage of $\mathrm{TlCaBaCuO}$ compound is the toxicity of thallium ( $\mathrm{Tl}$ ) which needs very careful processing and handling procedures. For microelectronic and microwave applications of $\mathrm{TlCaBaCuO}$ thin films, it is very important to establish a reproducible fabrication process for superior electrical and microwave properties.

The foremost applications of high- $T_{c}$ thin films is expected to be in the area of "passive microwave devices" such as resonators and filters. High- $T_{\mathrm{c}}$ superconducting thin films have lower surface resistance $R_{s}$ compared to $\mathrm{Cu}$ and $\mathrm{Au}$, corresponding to higher $Q$ and improved performance in passive microwave devices. TICaBaCuO thinfilm-based passive microwave devices have shown superior

(C) J. Appl. Phys. 72 (6), 15 September 1992. Reprinted, with permission, from American Institute of Physics. 
performances. Chang et al. ${ }^{5}$ have reported a surface resistance at least an order smaller than $\mathrm{Cu}$ at $77 \mathrm{~K}$ and 9.5 $\mathrm{GHz}$. Bourne et al. ${ }^{6}$ reported a $1 \mathrm{~ns}$ microstrip delay line using thin films of $\mathrm{TlCaBaCuO}$, again a factor of $10 \mathrm{im}$ provement in loss was observed at $3.29 \mathrm{GHz}$ and $77 \mathrm{~K}$. Hammond et al. ${ }^{7}$ reported a $\mathrm{TlCaBaCuO}$ microstrip resonator and its power handling performance at $77 \mathrm{~K}$. At effective power levels in the resonator up to $100 \mathrm{~W}$, the $Q$ was still three times higher than a silver resonator at 2.6 , 5.2 , and $7.3 \mathrm{GHz}$. Linear resonators with loaded $Q$ as high as 15000 at $5 \mathrm{GHz}$ have been demonstrated. ${ }^{8}$

This paper describes the processing and electrical transport measurements for achieving reproducible high$T_{c}$, high current density $J_{c}$, low microwave surface resistance $R_{s}$ TICaBaCuO thin films on $\mathrm{LaAlO}_{3}$ substrates, for microelectronic applications. A method for fabricating low-resistance contacts on $\mathrm{TlCaBaCuO}$ thin films for reliable electrical transport measurements is also addressed. The microwave properties of $\mathrm{TlCaBaCuO}$ thin films were investigated by designing, fabricating, and characterizing microstrip ring resonators for $12 \mathrm{GHz}$ fundamental resonance frequency. This paper describes the results of these investigations.

\section{EXPERIMENTAL}

TlCaBaCuO thin films were sputter deposited from a single composite powder target in a CVC model 601 if sputtering system operating at $13.56 \mathrm{MHz}$. The system was operated in the $\mathrm{rf}$ magnetron mode to improve the sputtering yields at low working pressures. The depositions were performed in a "sputter up" configuration on substrates placed face down. The $\mathrm{Tl}_{2} \mathrm{Ca}_{2} \mathrm{Ba}_{2} \mathrm{Cu}_{3} \mathrm{O}_{x}$ powder target was prepared by the solid-state reaction of stoichiometric amounts of high-purity $\mathrm{BaO}, \mathrm{CaO}, \mathrm{CuO}$, and $\mathrm{Tl}_{2} \mathrm{O}_{3}$ (in the ratio $2: 2: 2: 3$ ) powders. The target was enriched with $20 \%$ excess $\mathrm{Tl}_{2} \mathrm{O}_{3}$ to compensate for the loss of $\mathrm{Tl}$ during the postprocessing of the thin films, and to maintain sufficient composition for several deposition runs. The powder target was spread over an 8-in.-diam copper plate which was part of the cathode assembly, and pressed to obtain a uniform surface. The (100) $\mathrm{LaAlO}_{3}$ substrates were degreased in acetone, methanol, rinsed in de-ionized (DI) water, and blown dry using nitrogen before loading into the vacuum chamber. Depositions were performed at a if power density of $0.7 \mathrm{~W} / \mathrm{cm}^{2}$, and a chamber pressure at $5 \mathrm{mTorr}$, in a pure argon atmosphere. The thin films were deposited to a thickness of about $3000-5000 \AA$, at a deposition rate of approximately $30 \AA / \mathrm{min}$, as determined by Dektak profilometer thickness measurements. The detailed fabrication process has been described earlier by the authors. ${ }^{12}$

The sputter-deposited thin films of $0.3-0.5 \mu \mathrm{m}$ thickness were postprocessed in two steps: first, sintering in air at $850^{\circ} \mathrm{C}$ (to create the $\mathrm{Tl}_{2} \mathrm{O}$ liquid phase), in an excess $\mathrm{Tl}$ partial pressure; and second, annealing in flowing oxygen at about $750^{\circ} \mathrm{C}$ in an excess $\mathrm{Tl}$ partial pressure. These processes were performed in a small box furnace with the samples placed in an enclosed platinum crucible in the free-surface configuration described by Ginley et al."

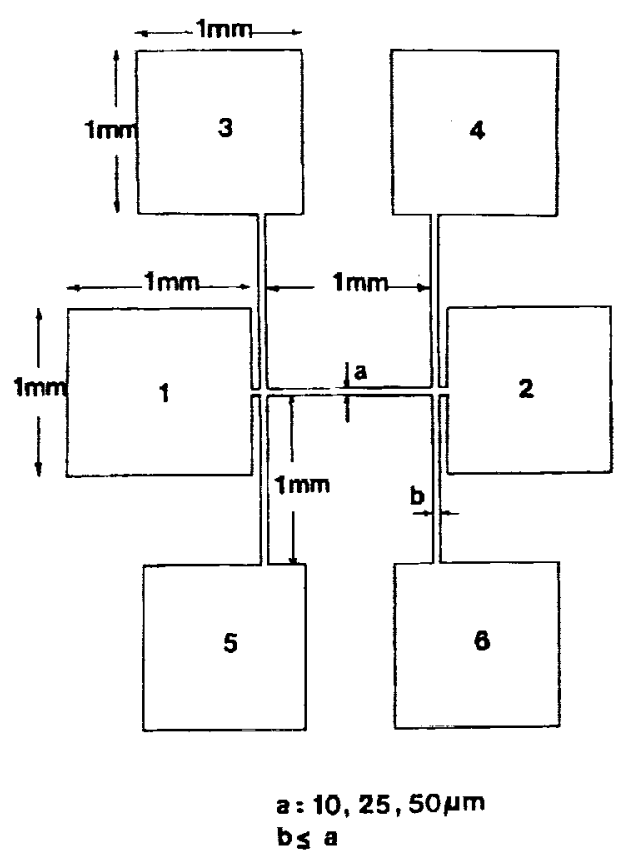

FIG. 1. The geometry of four-probe test devices with linewidths of 10,25, and $50 \mu \mathrm{m}$ for electrical-transport measurements. The voltage sense lines are $1 \mathrm{~mm}$ apart.

The thin films were placed on a $\mathrm{Tl}_{2} \mathrm{Ca}_{2} \mathrm{Ba}_{2} \mathrm{Cu}_{3} \mathrm{O}_{x}$ pellet, with the film side facing the free surface in an enclosed platinum crucible. A second pellet was placed on a platinum wire mesh, approximately half an inch above the thinfilm surface. The pellets provided the excess $\mathrm{Tl}$ partial pressure inside the crucible, mainly to minimize the loss of $\mathrm{Tl}$ from the thin films. The details of the post-processing heat treatments has been reported earlier. ${ }^{11,12}$ For reproducible processing of $\mathrm{TICaBaCuO}$ thin films, it was necessary to provide the optimum Tl partial pressure during postdeposition processes. A simple technique was used to monitor the reduction in $T 7$ content in the as-deposited thin films, after each sputtering run. The percentage reduction in $\mathrm{Tl}$ content from run to run was obtained through Auger electron spectroscopy (AES) surface analysis on the asdeposited samples. The percentage reduction in $\mathrm{Tl}$ content compared to a standard reference 2223 pellet gives an approximate estimate of additional $\mathrm{Tl}$ partial pressure needed during the postdeposition processes. The estimated additional $\mathrm{Tl}$ partial pressure was provided for the postdeposition processes by adding additional 2223 pellets in the crucible. This technique has yielded reproducible high- $T_{c}$ and high- $J_{c}$ films. ${ }^{14}$

For the electrical-transport measurements, four-probe test devices were designed with linewidths of 10,25 , and 50 $\mu \mathrm{m}$. The geometry of the test devices is shown in Fig. 1. The voltage sense lines were $1 \mathrm{~mm}$ apart, and the width of the sense lines was less than the linewidths in order to approximate a point contact as closely as possible. The test devices were patterned on as-deposited $\mathrm{TlCaBaCuO}$ thin films using standard photolithography and wet chemical 
etching techniques. Positive photoresist $A Z 1421$ was used for the lithography. The as-deposited $\mathrm{TlCaBaCuO}$ thin films on $\mathrm{LaAlO}_{3}$ substrates were prebaked at $180^{\circ} \mathrm{C}$ for 20 min before the photoresist was spun. The photoresist $\mathrm{AZ}$ 1421 was spun on to a thickness of about $1 \mu \mathrm{m}$. The samples were soft baked at $90^{\circ} \mathrm{C}$ for $20 \mathrm{~min}$, followed by exposure to UV light in a mask aligner. The photoresist was developed in a 1:5 developer:DI $\mathrm{H}_{2} \mathrm{O}$ solution for $45 \mathrm{sec}$. The samples were postbaked at $85^{\circ} \mathrm{C}$ for $15 \mathrm{~min}$ to complete the photolithography process. A 1:90 phosphoric acid:DI $\mathrm{H}_{2} \mathrm{O}$ solution was used for chemically etching the films. The solution was kept at a constant temperature of $75^{\circ} \mathrm{C}$. The etch rate was approximately $40 \AA / \mathrm{min}$. After the etching process was completed, the photoresist was removed by immersing the samples in acetone for $25 \mathrm{~s}$, followed by a $30 \mathrm{~s}$ rinse in DI $\mathrm{H}_{2} \mathrm{O}$. The patterned samples were postprocessed using our standard methods described above.

For electrical measurements on the test devices, metal bonding pads were formed by thermally evaporating 6000 $\AA$-thick gold film on the superconducting pads, through a shadow mask. In order to obtain low-resistance contacts, the samples were annealed in an oxygen flow of $1 \mathrm{l} / \mathrm{min}$, for about $15 \mathrm{~min}$ at $600^{\circ} \mathrm{C}$, followed by slow furnace cooling for $30 \mathrm{~min}$ after the furnace was switched off. The samples were removed when the furnace temperature was approximately $300^{\circ} \mathrm{C}$. Gold wires of $1 \mathrm{mil}$ diameter were bonded to the gold pads using a Kulicke and Soffa Model 4123 ultrasonic wedge bonder. The bonding process did not require sample heating. For redundancy, multiple bonds were attached on the contact pads.

The zero-resistance $T_{c}$ of the test devices was determined by measuring the resistivity versus temperature characteristics. The critical transport $J_{c}$ was measured using $\mathrm{dc}$ and pulsed-cúrrent techníques, using a $1 \mu \mathrm{V} / \mathrm{mm}$ electric-field criterion. A Keithley model 181 nanovoltmeter and a Keithley model 224 current source were used for the dc transport measurements. The specimen temperature was controlled using a Lakeshore model 805 temperature controller, connected to a closed-cycle helium gas refrigeration system. The error in temperature measurement was less than $0.25 \mathrm{~K}$. Thermal equilibrium was established before measurements at each temperature below $T_{c}$. The dc current method was not used above a current density of $10^{4} \mathrm{~A} / \mathrm{cm}^{2}$, since sample heating at higher currents could cause the films to crack before measurements could be completed.

The pulsed current measurements were performed using two EG\&G PARC 5210 lock-in amplifiers, a HP 214B pulse generator, and an adjustable current source capable of supplying $1 \mathrm{~A}$. The pulse generator supplies a $10 \mathrm{~V}, 1$ $\mathrm{KHz}$ pulse train with a $10 \%$ duty cycle. The puised current is applied to the test device, and the corresponding voltage pulse is measured across the sample using the lockin amplifiers. The amplitude of the current pulse at which the voltage across the sample exceeds $1 \mu \mathrm{V}$ yields the critical current at a particular temperature. The pulsed current measurements were compared to the dc values at as many temperatures as possible to insure the accuracy and com-

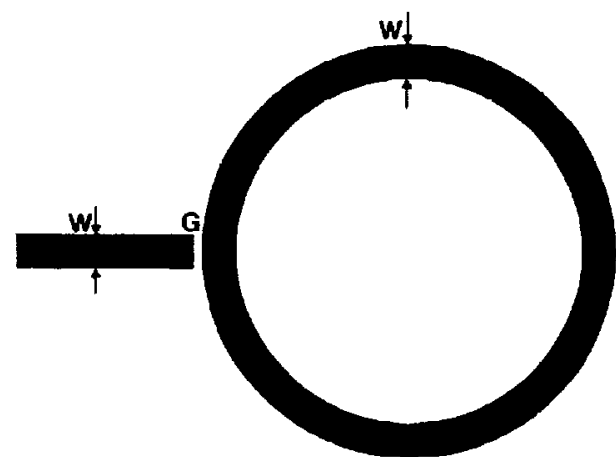

FIG. 2. Microstrip ring resonator designed for the fundamental resonance at $12 \mathrm{GHz}$. The coupling 8 ap $G$ and width $W$ were chosen at 1.75 and 5.6 mils, respectively.

patibility of the two methods. The morphology of the finished TICaBaCuO devices was examined in an ISI SX-30 scanning electron microscope (SEM). The morphology was evaluated in order to study the correlation between $J_{c}$ and the microstructure of the films.

A microstrip resonator is a useful device for measurement of dispersion, phase velocity, and effective dielectric constants of dielectric substrates. Ring resonators are being widely used for realizing filters, and stabilization of oscillators. A microstrip ring structure resonates if its electrical length is an integral multiple of the guide wavelength. A simple ring resonator device was designed that consisted of a ring structure separated from the feed line by a small coupling gap. The size of the coupling gap determines the coupling between the feed line and the ring resonator. Loose coupling is desired to minimize excessive loading effects. $^{15}$ A ring resonator designed for 10-mil-thick $\mathrm{LaAlO}_{3}$ substrates $(\epsilon r=24.5)$, for a fundamental resonance at $12 \mathrm{GHz}$ is shown in Fig. 2. In the figure, the linewidth of the ring and the microstrip feed line is $W=5.6$ mils, the coupling gap $G=1.75$ mils, and the mean radius of the ring $R=(R 1+R 2) / 2=77$ mils. The characteristics impedance of the microstrip is $41 \Omega$ at $12 \mathrm{GHz}$. The details of the design of the ring resonator have been described by Chorey et al. ${ }^{15}$

$\mathrm{TlCaBaCuO}$ ring resonators were fabricated by patterning $0.3 \mu \mathrm{m}$ thin films using $\mathrm{AZ} 1421$ positive photoresist photolithography and wet chemical etching techniques similar to the process used for fabricating the four-probe test devices described above. The ring resonators were annealed using the same annealing procedure described above. The samples were divided into two groups: one set of samples with $1 \mu \mathrm{m}$ gold film on the bottom side of the $\mathrm{LaAlO}_{3}$ substrate for the ground plane formation and a second set with a $0.3 \mu \mathrm{m} \mathrm{TlCaBaCuO}$ superconducting thin-film ground plane. The ground plane side superconductor was deposited and postprocessed using our routine postdeposition methods described above, after the microstrip ring resonator was fabricated on the top side.

A ring resonator was mounted in a gold-plated copper test fixture of $1 \mathrm{in}$. wide, $2 \mathrm{in}$. long, and $1 \mathrm{in}$. thick. The test 


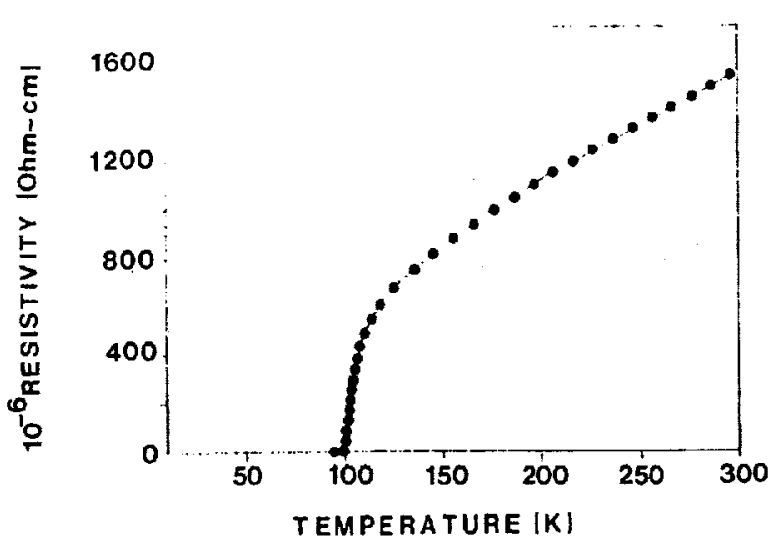

FIG. 3. The resistivity vs temperature characteristics of a patterned TlCaBaCuO thin-film test device, after lithography, chemical etching, and annealing, showing the onset of $T_{\mathrm{r}}$ at $106 \mathrm{~K}$ and zero resistivity at $98.5 \mathrm{~K}$.

fixture was placed on the cold head of the helium gas closed-cycle cryogenic system. ${ }^{12}$ Electrical connection to the feed line was obtained by mechanical contact of a launcher at the input side of the test fixture. Connections to the HP 8720 network analyzer were made using a 0.141 in. semirigid coaxial cable of $50 \Omega$ characteristic impedance. Before measurements were performed on ring resonators, standard one-port calibration was performed at room temperature. The calibration was performed using an open, a short, and a broadband load to effectively remove the test system imperfections introduced by the interconnecting cables, adapters, etc. The calibration was also valid at lower temperatures.

\section{RESULTS}

The resistivity versus temperature characteristics of a $50-\mu \mathrm{m}$-wide four-probe test device is shown in Fig. 3. The measurements were taken at a constant applied current of $10 \mu \mathrm{A}$. The onset of superconductivity occurred at $106 \mathrm{~K}$, and the device showed zero resistance at $98.5 \mathrm{~K}$. The room-temperature resistivity was $1.5 \times 10^{-3} \Omega \mathrm{cm}$. Zero resistance $T_{c}$ between 97 and $100 \mathrm{~K}$ is routinely obtained. The $T_{r}$ is low because of the $\mathrm{Tl}_{2} \mathrm{Ca}_{1} \mathrm{Ba}_{2} \mathrm{Cu}_{2} \mathrm{O}_{x}$ (2122) phase, which is the dominant phase in these films. The thin films were also characterized by $x$-ray-diffraction analysis (XRD), and the results showed the characteristic peaks of 2122 and 2223 phases. The 2122 phase with $c$-axis-oriented growth was the dominant phase in the $\mathrm{TlCaBaCuO}$ thin films, as determined from the XRD data. The details of the XRD analysis are reported by the authors elsewhere. ${ }^{13}$

The contact resistance obtained from four-probe resistance measurements is typically a few $\mathrm{m} \Omega$, at temperatures below the $T_{c}$. The specific contact resistivity calculated from the four-probe resistance measurements range from $3.65 \times 10^{-5} \Omega \mathrm{cm}^{2}$ at $90 \mathrm{~K}$, to $10^{-10} \Omega \mathrm{cm}^{2}$ below $77 \mathrm{~K}$, These results were reproducible from sample to sample and are comparable with the results for $\mathrm{Au}$ contacts on $\mathrm{YBaCuO}$ high-temperature superconducting thin films.

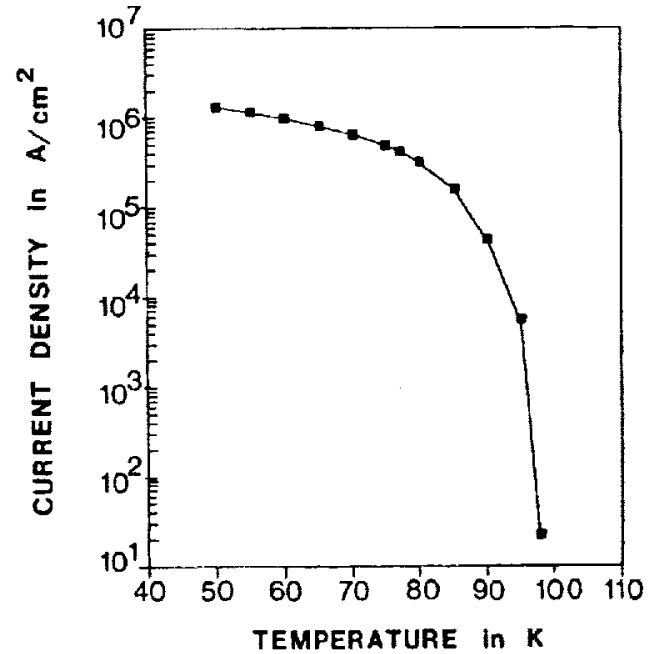

FIG. 4. Typical zero-field current density $J_{c}$ vs temperature characteristics of a TiCaBaCuO four-probe test device obtained using the $1 \mu \mathrm{V} / \mathrm{mm}$ electric-field criterion.

Figure 4 shows the typical zero-field current density $J_{c}$ versus temperature measurements obtained on the fourprobe test devices. Current densities at zero magnetic field as high as $5 \times 10^{5} \mathrm{~A} / \mathrm{cm}^{2}$ at $77 \mathrm{~K}$ an approximately $1 \times 10^{6}$ $\mathrm{A} / \mathrm{cm}^{2}$ at $60 \mathrm{~K}$ were obtained. The resistivity of the sample calculated from the $I-V$ measurements is approximately $2.38 \times 10^{-11} \Omega \mathrm{cm}$ at $77 \mathrm{~K}$, much lower than any normal conductors at this temperature. The surface morphology of one of the test devices is shown in Fig. 5. The surface was essentially featureless and very smooth, typical of highquality films. The current density of such films exceeded $10^{5} \mathrm{~A} / \mathrm{cm}^{2}$ at $77 \mathrm{~K}$. Films with numerous intergrain boundaries showed lower current densities below $10^{4} \mathrm{~A}$ / $\mathrm{cm}^{2}$ at $77 \mathrm{~K}$.

The resonator quality factor $Q$, the ratio of the energy stored in the resonator to the energy dissipated in the resonator, was obtained from swept frequency reflection mea-

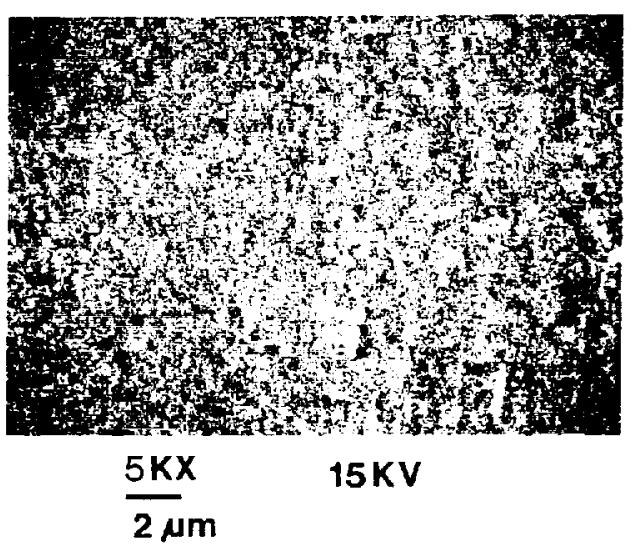

FIG. 5. Scanning electron micrograph of a $\mathrm{T} / \mathrm{CaBaCuO}$ thin-film surface showing a smooth featureless morphology. The marker is $2 \mu \mathrm{m}$ long. 


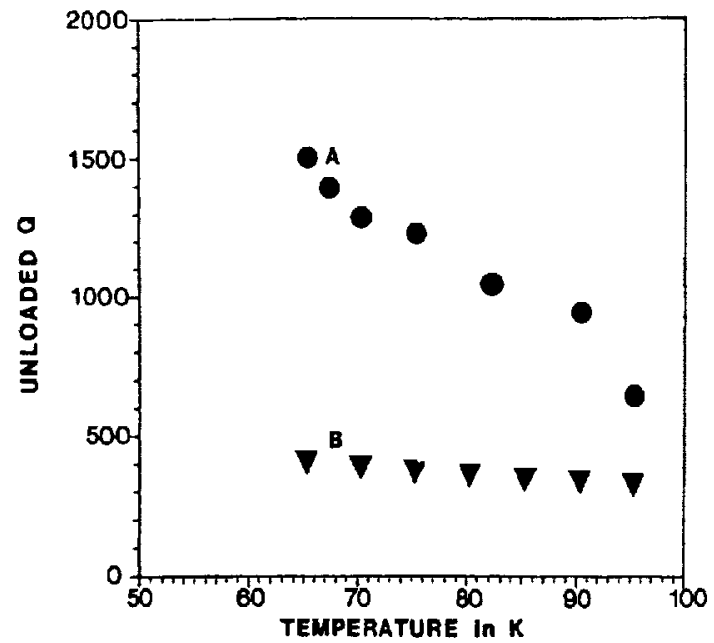

FIG. 6. The unloaded $Q$ vs temperature characteristics of a $\mathrm{TlCaBaCuO}$ microstrip ring resonator. Curve $A$ is for a superconducting ring resona. tor with a $0.3 \mu \mathrm{m} \mathrm{TlCaBaCuO}$ ground plane, and curve B is for a gold ring resonator.

surements. ${ }^{15,16}$ The $Q$ value is a figure of merit for a resonator, and is inversely proportional to the total losses in the circuit. The measured $Q$ (called the loaded $Q$ ) is a measure of the circuit losses including the coupling loss and the loss through the feed line. The actual $Q$ of the ring resonator (called the unloaded $Q$ ) is a measure of the losses only in the resonator. The unloaded $Q$ is obtained by separating the external losses in the feed line and due to coupling. The loaded $Q$ and the unloaded $Q$ are related through the reflection coefficients at and far from resonance. ${ }^{16}$ The derivation for the relationship between the loaded $Q$ and the unloaded $Q$ is described by Aitken. ${ }^{16} \mathrm{~A}$ computer program was written to compute the unloaded $Q$ values from the measured loaded $Q$ and the magnitude of reflection coefficients at and far from resonance. The determination of whether the resonator was overcoupled or undercoupled was made from the Smith chart and also the phase response of the resonator. Typically, the ring resonators were overcoupled. Measurements for the superconducting resonator were performed at the fundamental resonance frequency of $12 \mathrm{GHz}$ and an input power level of $-30 \mathrm{dBm}$.

Unloaded $Q$ versus temperature characteristics for two ring resonators is shown in Fig. 6. Curve $A$ is the data for the high- $T_{c}$ thin-film ring resonator with a superconducting ground plane. For comparison, data for the gold resonator with a gold ground plane is shown by curve $B$. The unloaded $Q$ of the ring resonator with superconducting ground plane is approximately four times higher than the gold resonator at $65 \mathrm{~K}$. In addition, the unloaded $Q$ of the superconducting ring resonator shows an increasing trend in $Q$ with decreasing temperature, whereas the superconducting ring resonators with gold ground plane show a saturation of $Q$ at low temperatures due to the dominance of ground plane conductor losses.

The superconducting ring resonators offer an indirect method for measuring the surface resistance $R_{\mathrm{s}}$ of the su-

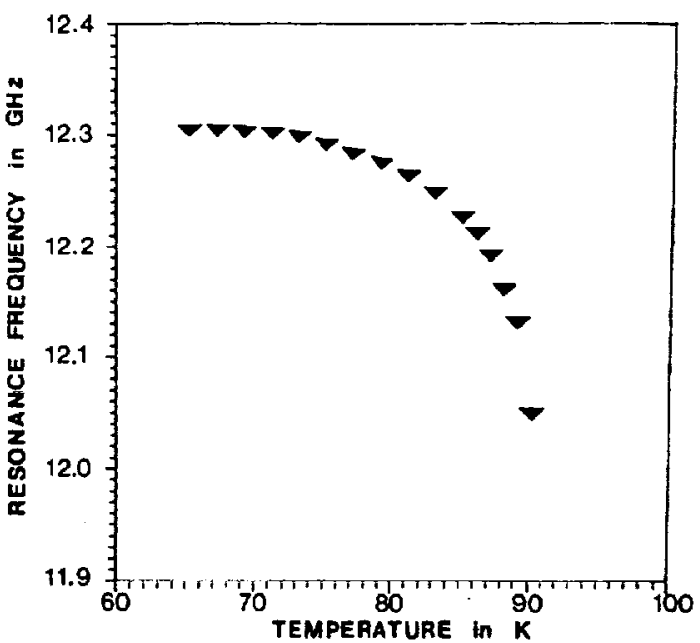

FIG. 7. The resonance frequency shift ws temperature characteristics of a $\mathrm{TICaBaCuO}$ ring resonator.

perconducting thin films. This microwave surface resistance is the fundamental quantity responsible for the conductor losses at high frequencies. The $R_{s}$ of sputtered thin films were obtained from ring resonator quality factor $Q$ measurements. By separating the conductor and dielectric losses, the surface resistance of the $\mathrm{TlCaBaCuO}$ thin films was calculated using the standard microstrip loss equations described by Pucel, Masse, and Hartwig. ${ }^{17}$ The $R_{s}$ at 12 $\mathrm{GHz}$ and $77 \mathrm{~K}$ was determined to be typically between 1.5 and $2.75 \mathrm{~m} \Omega$, almost an order of magnitude lower than $R_{s}$ of $\mathrm{Cu}$ at the same temperature and frequency.

The swept frequency refleation measurements performed at several temperatures are also used in determining the penetration depth of the $\mathrm{TlCaBaCuO}$ superconducting thin films. The resonance frequency is the frequency at which the magnitude of the reflection coefficient is at the minimum. The resonance frequency was measured at each temperature for ring resonators. A typical measured resonance frequency shift with respect to temperature for a superconducting ring resonator with an approximately $1-\mu \mathrm{m}$-thick gold ground plane is shown in Fig. 7. The shift in resonance frequency with temperature is mainly due to the temperature dependence of the penetration depth of the superconductor. Thus, the resonance frequency shift is an indirect method of determining the penetration depth. From the figure, the change in resonance frequency below $70 \mathrm{~K}$ is almost negligible. The superconducting resonators with a $0.3-\mu \mathrm{m}$-thick superconducting ground plane showed a slightly higher dependence of resonance frequency with temperature due to the temperature dependence of penetration depths of the top and the ground plane superconductors. A detailed analysis of this figure to determine the penetration depth of the superconducting thin films is given in the following section.

\section{ANALYSIS AND DISCUSSIONS}

The data from the zero-field current density $J_{c}$ measurements shown in Fig. 4 were analyzed to investigate the 
dependence of $J_{c}$ with the temperature ratio $T / T_{c}$. The slope of the $\log J_{c}$ vs $\log \left(1-T / T_{c}\right)$ characteristics is an indication of the type of the superconductor. The slope of the line obtained from our measurements was approximately 1.5 for temperatures between 50 and $80 \mathrm{~K}$. The $\left(1-T / T_{c}\right)^{3 / 2}$ dependence of $J_{c}$ is consistent with earlier reports in high- $T_{c}$ thin films. ${ }^{18}$ This indicates that the thin films may contain grain boundaries that are either insulating or behave like a normal metal, or the thin films may be polycrystalline in nature. The presence of grain boundaries and weak flux pinning in $\mathrm{TlCaBaCuO}$ thin films may be the main reasons for the lower $J_{c}$ in $\mathrm{TlCaBaCuO}$ thin films compared to epitaxial in situ grown $\mathrm{YBaCuO}$ thin films. However, among the polycrystalline high- $T_{c}$ thin films, $\mathrm{TlCaBaCuO}$ thin films have shown superior electrical properties and hence are very attractive for electronic applications.

The penetration depth of $\mathrm{TICaBaCuO}$ thin films can be determined from the resonance frequency versus temperature measurements, by comparing the experimental data shown in Fig. 7 with theoretical calculations. The resonance frequency shift in the ring resonators is assumed to be due to the change in penetration depth with temperature. Neglecting the effects due to the substrate contraction at lower temperatures, the penetration depth was extracted from the resonance frequency shift as discussed below.

The phase velocity of a superconducting microstrip transmission line with a superconducting ground plane is given by ${ }^{19}$

$$
v_{\mathrm{ph}}=c / \sqrt{\epsilon_{\mathrm{eff}}}[1+2 \lambda / h \operatorname{coth}(t / \lambda)]^{-0.5},
$$

where $c$ is the velocity of light, $\epsilon_{\text {eff }}$ is the effective dielectric constant, $h$ is the substrate thickness, $t$ is the thickness of the microstrip, and $\lambda$ is the penetration depth of the superconducting microstrip. The penetration depth is temperature dependent based on the Gorter-Casimir relationship, ${ }^{20}$ i.e.,

$$
\lambda(T)=\lambda(0)\left[1-\left(T / T_{c}\right)^{4}\right]^{-0.5},
$$

for temperature $T$ less than $T_{c^{\prime}} \lambda(0)$ is the penetration depth at $t=0 \mathrm{~K}$. The resonance frequency of the ring resonator is given by the equation

$$
f=n v_{\mathrm{ph}} /(2 L)
$$

where $f$ is in $\mathrm{GHz}, L$ is the mean circumference of the ring in $\mathrm{mm}$, and $n$ is the integer order of resonance. From the temperature dependence of resonance frequency measurements and the above equations, the best value of $\lambda(0)$ was determined to be $6890 \AA$. The typical value ranges between 7000 and $8000 \AA$. This is an approximate estimate for the penetration depth along the $c$ axis in the TICaBaCuO thin films. Since the thin films are only $0.3-0.4 \mu \mathrm{m}$ thick, the penetration depth depends upon the properties of the superconductor through the entire film. This may be a reason for the high penetration depth. Also, the patterned thin films have rough edges, and hence the penetration depth obtained using the above technique is an averaged value over the whole film area.
The surface resistance of the $\mathrm{TlCaBaCuO}$ superconducting thin films determined from the ring resonator $Q$ measurements was compared with the theoretical surface resistance versus temperature characteristics for a given penetration depth. A theoretical model based on the phenomenological loss equivalence method (PEM) approximation 21,22 was employed to determine the theoretical variation of conductor losses and the surface resistance with temperature for the cases of superconducting microstrip/gold ground plane, and superconducting microstrip/ superconducting ground plane. Both these cases were compared to the attenuation constant of a gold microstrip on $\mathrm{LaAlO}_{3}$ substrate.

The attenuation constant for a superconducting $\mathrm{mi}$ crostrip is calculated from the formula ${ }^{22}$

$$
\begin{aligned}
\alpha= & \left(T / T_{c}\right)^{4} /\left[1-\left(T / T_{c}\right)^{4}\right]^{3 / 2}\left(G_{1} / 4\right)\left(\sigma_{n} / Z\right) \\
& \times \omega^{2} \mu^{2}\left[\lambda(0)^{3}\right] \operatorname{coth}(X)+X \operatorname{cosec}^{2}(X)(N p / m),
\end{aligned}
$$

where

$$
X=A\left[G_{1} / \lambda(0)\right]\left[1-\left(T / T_{c}\right)^{4}\right]^{1 / 2} .
$$

$G_{1}$ is the geometric factor given by the equation

$$
\begin{aligned}
G_{1}= & 1 /(\pi h)\left\{1-\left[W_{e} /(4 h)\right]^{2}\right\}\left[1 / 2+h / W_{e}\right. \\
& \left.+h /\left(\pi W_{e}\right) \ln (2 h / t)\right],
\end{aligned}
$$

where $W_{e}$ is the effective width of the microstrip, $A$ is the area of cross section of the microstrip, $T$ is the measurement temperature below $T_{\sigma}$ and $\lambda(0)$ the penetration depth at $0 \mathrm{~K}$ of the superconductor.

The parameters assumed for the calculations are the relative dielectric constant $\epsilon$, of $\mathrm{LaAlO}_{3}$ of 24.5 , the loss tangent $(\tan \delta)$ of $\mathrm{LaAlO}_{3}$ of $8.3 \times 10^{-5}$ below $100 \mathrm{~K}$, the substrate thickness $h$ of $10 \mathrm{mil}$, the width of the microstrip $W$ of $142 \mu \mathrm{m}$, corresponding to a characteristic impedance of $41 \Omega$ at $12 \mathrm{GHz}$, the thickness of the superconducting microstrip $t$ of $0.3 \mu \mathrm{m}$, the ground plane thickness of $1 \mu \mathrm{m}$ for a gold ground plane and $0.3 \mu \mathrm{m}$ for a superconducting ground plane, the zero resistance $T_{c}$ of the $\mathrm{TlCaBaCuO}$ thin films of $100 \mathrm{~K}$, and the normal conductivity at $T_{c}\left(\sigma_{n}\right)$ of $1.5 \times 10^{6} \mathrm{~S} / \mathrm{m}$.

The ground plane conductor losses can be calculated by the same method, using the geometric factor $G_{2}$ instead of $G_{1}$ in Eq. (4),

$$
G_{2}=1 /(2 \pi h)\left[1-\left(W_{e} / 4 h\right)^{2}\right] .
$$

Figure 8 shows temperature variation of the attenuation due to conductor losses for a gold microstrip (curve A), a superconducting microstrip with a gold ground plane (curve B), and a superconducting microstrip with a superconducting ground plane (curve $C$ ) as determined using Eqs. (4)-(6). The upper diagram is for $\lambda(0)$ of $6000 \AA$, and the lower diagram is for $\lambda(0)$ of $7000 \AA$. Figure 8 shows the lower attenuation for the microstrip with superconducting ground plane (curve $C$ ) compared to the one with gold ground plane (curve B) below $77 \mathrm{~K}$. 

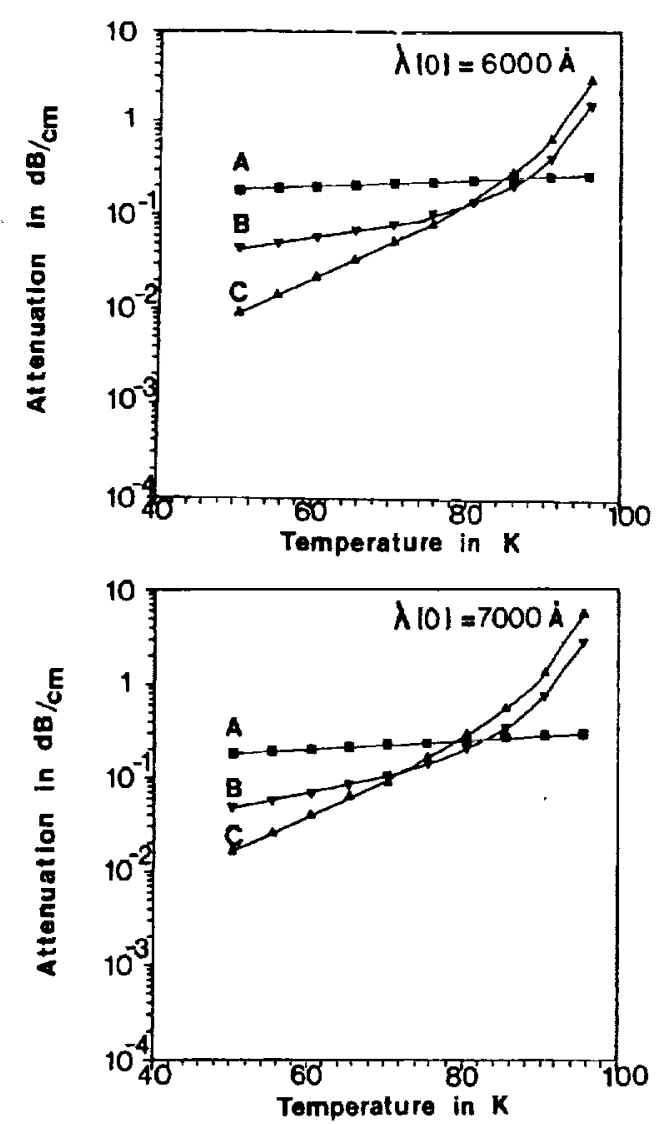

FIG. 8. Theoretical temperature variation of attenuation due to conductor losses for a gold microstrip (1- $\mu \mathrm{m}$-thick gold for both sides: curve A), a superconducting microstrip $(0.3 \mu \mathrm{m})$ with a gold ground plane $(1 \mu \mathrm{m})$ in curve $B$, and a superconducting microstrip $(0.3 \mu \mathrm{m})$ with a superconducting ground plane $(0.3 \mu \mathrm{m})$ in curve $C$. The penetration depth at $0 \mathrm{~K}$ was assurned to be $6000 \AA$ for the upper diagram and $7000 \AA$ for the lower diagram.

The surface resistance of the superconducting thin film is obtained from the equation

$$
R_{s}=2 Z_{0} \alpha / G_{1}
$$

where $Z_{0}$ is the characteristic impedance of the microstrip. The theoretical temperature variation of surface resistance of the superconducting microstrip with a superconducting ground plane determined using Eq. (7) is shown in Fig. 9, for $\lambda(0)$ of $6000 \AA$ (curve C) and $7000 \AA$ (curve B). For comparison, the surface resistance of a $1-\mu \mathrm{m}$-thick gold microstrip (curve A) on a $\mathrm{LaAlO}_{3}$ substrate is plotted for the same microstrip geometry. The $R_{s}$ calculated from the measured $Q$ values of an all-superconducting ring resonator on a $\mathrm{LaAlO}_{3}$ substrate (curve D) is also plotted in Fig. 9. The $R_{\text {s }}$ obtained from the ring resonator $Q$ measurements (curve $D$ ) deviates from the theoretical temperature dependence as seen in the figure. Since the TICaBaCuO thin films do react with the $\mathrm{LaAlO}_{3}$ substrate, it is possible that the region of interaction contributes to additional losses.

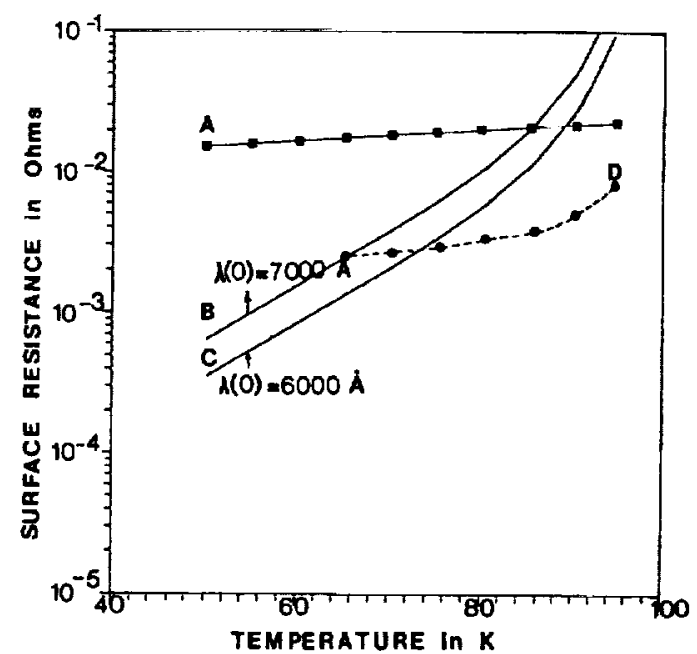

FIG. 9. Theoretical temperature variation of surface resistance for the all-superconducting ring resonator, for penetration depths at $0 \mathrm{~K}$ of 6000 (curve C) and $7000 \AA$ (curve $B$ ). The surface resistance calculated from the measured $Q$ values of the resonator is also shown in curve $D$. For comparison, the surface resistance of a gold microstrip is plotted in curve A.

\section{SUMMARY}

TlCaBaCuO superconducting thin films were fabricated on $\mathrm{LaAlO}_{3}$ substrates by rf magnetron sputter deposition in a pure argon plasma and by using postannealing techniques. A reproducible fabrication process has been established for $\mathrm{TlCaBaCuO}$ thin films on $\mathrm{LaAlO}_{3}$ substrates for high- $T_{c}$ and high- $J_{c}$ characteristics. The $\mathrm{TlCa}$ $\mathrm{BaCuO}$ thin films were patterned into four-probe test devices using standard microelectronic lithography and wet etching techniques. Low-resistance gold contacts on TICa$\mathrm{BaCuO}$ thin films were obtained by annealing at $600^{\circ} \mathrm{C}$ in an oxygen flow of $1 \mathrm{l} / \mathrm{min}$ followed by a slow furnace cooling for about $30 \mathrm{~min}$. The critical current density measurements were performed using $\mathrm{dc}$ and pulsed current techniques under the electric-field criterion of $1 \mu \mathrm{V} / \mathrm{mm}$. The zero-resistance $T_{c}$ between 97 and $100 \mathrm{~K}$ are routinely obtained in patterned $\mathrm{TlCaBaCuO}$ thin films. Zero-field current density $J_{c}$ as high as $5 \times 10^{5} \mathrm{~A} / \mathrm{cm}^{2}$ were obtained in four-probe test devices. The specific contact resistivity measured when the sample is superconducting ranges from $3.65 \times 10^{-5} \Omega \mathrm{cm}^{2}$ at $90 \mathrm{~K}$, to $10^{-10} \Omega \mathrm{cm}^{2}$ below $77 \mathrm{~K}$.

The microwave properties of $\mathrm{TlCaBaCuO}$ thin films were investigated by designing, fabricating, and characterizing a microstrip ring resonator. The resonator was designed for a fundamental resonance frequency of $12 \mathrm{GHz}$, and for fabrication on 10 -mil-thick $\mathrm{LaAlO}_{3}$ substrates. Ring resonators with a gold ground plane of $1 \mu \mathrm{m}$ thickness and a $\mathrm{TlCaBaCuO}$ superconducting ground plane of $0.3 \mu \mathrm{m}$ thickness were fabricated and characterized at cryogenic temperatures. The unloaded $Q$ for the superconducting resonators were above 1500 at $65 \mathrm{~K}$, compared to 370 for a gold resonator. The surface resistance of the $\mathrm{TlCaBaCuO}$ thin films obtained by separating conductor losses from the $Q$ measurements is typically between 1.5 
and $2.75 \mathrm{~m}-\Omega$ at $12 \mathrm{GHz}$ and $77 \mathrm{~K}$, almost an order lower than $\mathrm{Cu}$ and $\mathrm{Au}$ at the same temperature and frequency. The penetration depth at $0 \mathrm{~K}$ was calculated from the resonance frequency shift with temperature measurements. The typical values for the penetration depth at $0 \mathrm{~K}$ are approximately between 7000 and $8000 \AA$.

The conductor losses in the superconducting microstrips with superconducting ground plane were compared to the ones with gold ground plane using a theoretical model called the phenomenological loss equivalence method (PEM). This model predicted lower conductor losses for the microstrip with a superconducting ground plane, below $77 \mathrm{~K}$. A theoretical temperature variation of the surface resistance $R_{s}$ for different penetration depths was obtained for the all-superconducting microstrip (with superconducting ground plane). The $R_{s}$ obtained from the $Q$ measurements in the ring resonators deviates from the theoretical temperature dependence. This is possibly because of additional losses introduced in the devices due to interaction between the $\mathrm{TlCaBaCuO}$ thin films and the $\mathrm{LaAlO}_{3}$ substrates. Nevertheless, the polycrystalline TICa$\mathrm{BaCuO}$ thin films have almost an order-of-magnitude lower surface resistance compared to gold at $80 \mathrm{~K}$. The design of the ring resonator was not optimized for the highest $Q$, but the results of our investigations show that $\mathrm{TlCaBaCuO}$ ring resonator devices fabricated with a superconducting ground plane do show higher $Q$ compared to a gold resonator below $90 \mathrm{~K}$, proving their usefulness for all-superconducting microwave circuit applications.

\section{ACKNOWLEDGMENTS}

The authors thank Dr. Regis Leonard for his continued support and encouragement. The authors thank Dr. Sam Alterovitz, Dr. Mark Stan, and Dr. John Pouch for useful discussions, and also thank Professor Punit Boolchand for his useful suggestions and discussions. This research was supported by NASA Lewis Research Center.
'J. G. Bednorz and K. A. Muller, Z. Phys. B 64, 189 (1986).

${ }^{1}$ M. K. Wu, J. R. Ashburn, C. J. Torng, P. H. Hor, R. L. Meng, L. Gao, Z. J. Huang. Y. Q. Wang, and C. W. Chu, Phys. Rev. Lett. 58, 908 (1987).

'H. Maeda, Y. Tanaka, M. Fukitomi, and T. Asano, Jpn. J. Appl. Phys. 27, L209 (1988).

Z. Z. Sheng and A. M. Hermann, Nature 332, 138 (1988).

${ }^{5}$ L. D. Chang, M. J. Moskowitz, R. B. Hammond, M. M. Eddy, W. L. Olson, D. D. Casavant, E. J. Smith, M. Robinson, L. Drabeck and G. Gruner, Appl. Phys. Lett. 55, 1357 (1989).

${ }^{6}$ L. C. Bourne, R. B. Hammond, McD. Robinson, M. M. Eddy, W. L. Olson, and T. W. James, Appl. Phys. Lett. 56, 2333 (1990).

${ }^{7}$ R. B. Hammond, G. V. Negrete, M. S. Schmidt, M. J. Moskowitz, M. M. Eddy, D. D. Strother, and D. L. Skoglund, in Proceedings of the IEEE MTT Symposium, June 1990.

${ }^{8}$ C. Wilker, Z Y. Shen, P. Pang, D. W. Face, W. L. Holstein, A. L. Mathews, and D. B. Laubacher, IEEE Microwave Theory Tech. MTT39, 1462 (1991).

${ }^{9}$ S. S. P. Parkin, V. Y. Lee, E. M. Engler, A. I. Nazzal, T. C. Huang, O. Gorman, R. Savoy, and R. Beyers, Phys. Rev. Lett. 60, 2539 (1988).

${ }^{10}$ W. Y. Lee, V. Y. Lee, J. Salem, T. C. Huang, R. Savoy, D. C. Bullock, and S. S. P. Parkin, Appl. Phys. Lett. 53, 329 (1988).

"D. S. Ginley, J. F. Kwak, E. L. Venturini, B. Morosin, and R. J. Baughman, Physica C 160, 42 (1989).

${ }^{12}$ G. Subramanyam, F. Radpour, V. J. Kapoor, and G. H. Lemon, J. Appl. Phys. 68, 1157 (1990).

"G. Subramanyam, F. Radpour, and V. J. Kapoor, A ppl. Phys. Lett. 56, 799 (1990).

${ }^{14}$ G. Subramanyam, V. J. Kapoor, and G. H. Lemon, Bull. Am. Phys. Soc. 36, 519 (1991).

${ }^{15} \mathrm{C}$. M. Chorey, K. S. Kong. K. B. Bhasin, J. D. Warner, and T. Itoh, IEEE Trans. Microwave Theory Tech. 39, 1480 (1991).

${ }^{10}$ J. Aitken, Proc. Inst. Electr. Eng. 123, 855 (1976).

${ }^{17}$ R. A. Pucel, D. J. Masse, and C. P. Hartwig, IEEE Trans. Microwave Theory Tech. MTT-16, 342 (1968); 16, 1064 (1968)

18. F. Kwak, D. S. Ginley, E. L. Venturini, B. Morosin, R. J. Baughman, J. C. Barbour, and M. O. Eatough, in Studies of High Temperalure Superconductors, edited by A. Narlikar (Nova Science, New York, 1991), Vol. 7, pp. 45-73.

${ }^{19}$ R. L. Kautz, J. Appl. Phys. 49, 308 (1978).

${ }^{20} \mathrm{~T}$. Van Duzer and C. W. Tumer, Principles of Superconductive Devices and Circuits (Elsevier/North-Holland, New York, 1981), Chap. 3, pp. 92-138.

${ }^{21}$ H. - Y. Lee and T. Itoh, IEEE Trans. Microwave Theory Tech. MTT. 37, 1904 (1989)

${ }^{22} \mathrm{O}$. R. Baiocchi, K. -S. Kong, H. Ling, and T. Itoh, IEEE Microwave Guided Wave Lett. MGWL-1, 2 (1991). 